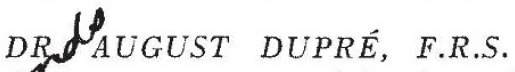

WEL-KNOWN name vanishes from the list of A finng analytical chemists by the death of Dr. ADlipré, which occurred at Sutton on July I5.

Like a number of chemists whose names readily come to mind-Hoffmann, Schorlemmer, and Lunge, for example-Dupré was born and educated in Germany, but in early manhood crossed the North Sea to seek a sphere for his talents in England. He had studied chemistry under Bunsen; and in 1855 , at the age of twenty, he graduated at Heidelberg with the degree of Ph.D. Coming soon afterwards to this country, his first appointment of importance was that of lecturer in chemistry at Westminster Hospital, in 1864. Two years later he became a naturalised British subject. Concurrently with his lecturing duties, Dupré also undertook those of chemical referee to the medical department of the Local Government Board and public analyst for Westminster; and for many years he was chemical adviser to the explosives department of the Home Office, a position which he held at the time of his death.

As might be expected, Duprés original work in chemistry bore chiefiy upon points arising in his own domain of chemical analysis. Some two dozen communications appeared during the period $1876-1902$ in the Analyst, the Journals of the Chemical Society and the Society of Chemical Industry, and in the Proceedings of the Royal Society. None were epochmaking, but all were useful; their general character will be shown by the titles of a few of them :-_"The Composition and Analysis of Butter Fat" (I876); "On Copper in Food" (1877); "The Estimation of Urea by Means of Hypobromite" ( 1877 ); "On the Estimation of Dissolved Oxygen in Water " (1885); "Changes in the Proportion of Acid and Sugar present in Grapes during Ripening "; "The Specific Heat and other' Physical Characters of Mixtures of Methyl Alcohol and Water"; "The Explosion of Potassium Chlorate by Heat"' (I902). In addition, Dupré made various reports upon explosives, and was joint author with Drs. Thudichum and Hake respectively of two well-known treatises, viz., "The Origin, Nature, and Varieties of Wines," and "A Short Manual of Inorganic Chemistry."

The crown of Duprés professional career was his election to the Royal Society in 1875 . To the general public, however, he was probably best known as the analyst whose dangerous duty it was to examine the explosives used in the Fenian scares of a generation ago-notably the one in which nitroglycerine was found in process of manufacture on a large scale at Birmingham in $188_{3}$.

Concerned chiefly with the practical applications of chemistry, Dupré was no leader in its philosophy, but his name is honourably associated with the advancement in this country of the profession he adopted when making this country his home.

C. S.

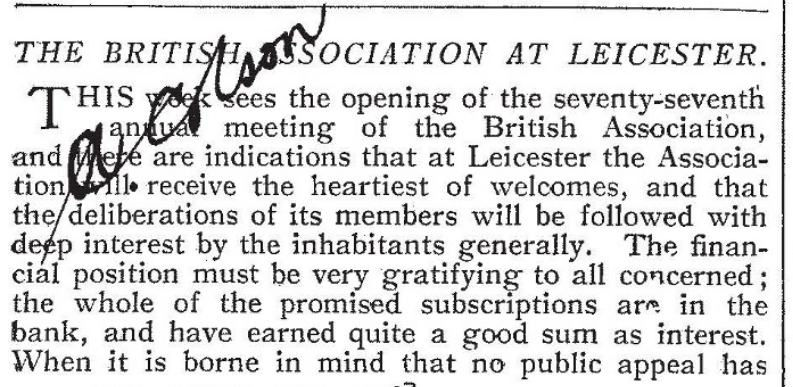

been made, but that the money has readily been subscribed, this happy result speaks highly as to the generosity of the townspeople and the manner in which they have been approached.

The Mayor (Sir Edward Wood) is most anxious that Leicester should prove its full appreciation of having been chosen as this year's meeting place, and that the many visitors to the ancient borough should carry away a lasting impression of its hospitality and desire for comfort. The local programme tells of Sir Edward Wood's wish to come into as close touch as possible with every visitor, in its record of an evening fête in the Abbey Park at which it is anticipated 3000 will be present. His Worship is supplementing this by entertaining on the following evening the officials of the Corporation, the teachers of the town, infirmary nurses, \&c., and he has invited the old people from the Trinity Hospital, almshouses, the cripples of the town, and others, to meet him in the same park on the Saturday-all this in commemoration of the visitwhich he desires should be a lasting, pleasurable recollection.

We have already spoken of the excellent arrangements made by the local executive, with Mr. Alfred Colson as its chairman, of the sectional meetings, interesting excursions and visits to works planned to add to the enjoyment of the men of science. Each member attending the meeting is to receive a copy of the special edition of "Glimpses of Ancient Leicester," a book written by a Leicester lady, and also to have a capital guide to Leicester and neighbourhood, with a map, prepared under the direction of the publications subcommittee, and containing specially written articles by experts on Charnwood Forest; stone roads, canals, edge-railways, outramways, . railways, \&c., of Leicestershire; geology; the pre-Cambrian rocks; palæontology, cryptogamic flora of Leicestershire; botany; zoology; entomology ; and a bibliography of town and county. These, it is hoped, will serve as memoirs of the town's welcome and a most successful week's work.

The Mayor, Recorder, Town Clerk, and others will attend the official service at St. Martin's Church on the Sunday morning, at which the Bishop of Southwark (Dr. Talbot) will preach. The Bishop of the diocese (Dr. Carr Glynn) is giving an address at St. Peter's Church, and other eminent men are preaching at various churches and chapels, so that the harmony of religion and science will doubtless receive every justice. The leading clubs of the town have freely opened their doors to "temporary members," and the full advantages of golfing and bowls are offered "to all interested.

The tramcar service of the town is a most complete one, and every facility for quick transit is given. A favourite daily rendezvous will undoubtedly be the "loggia" erected adjacent to, and connected with, the town museum buildings, and here, if the weather is fine, a quiet rest, a cup of tea, and the music ni the band of the Seaforth Highlanders will prove thoroughly enjoyable, and a relief to the heavier work of the sectional meetings.

Next year the Association is to meet at Dublin, and by a happy thought a deputation of the following gentlemen, Sir Howard Grubb, F.R.S., Rev. Dr. W. Delaney, and Prof. W. H. Thompson, will be the guests of the local executive at Leicester.

We hope that in a future issue we may be able to congratulate the Association on the complete success of its last annual meeting, the large attendance of its members, the high quality of the papers read and discussed and lectures given; and Leicester upon its generous welcome and hospitality.

NO. I970, VOL. 76] 
Inaugural AdpRess by Sir David Gill, K.C.B., LL.D., D.Sc., F.R.S., Hon. F.R.S.E., \&c., President of THE Associazion.

To-ny Hrit, for the first time in its history, the British Assaciation meets in the ancient city of Leicester; and it now becomes my privilege to convey to you, Mr. Mayor, ayd to the citizens generally, an expression of our thanks for your kind invitation and for the hospitable reception which you have accorded to us.

Here in Leicester and last year in York the Association has followed its usual custom of holding its annual meeting somewhere in the United Kingdom; but in 1905 the meeting was, as you know, held in South Africa. Now, having myself only recently come from the Cape, I wish to take this opportunity of saying that this southern visit of the Association has, in my opinion, been productive of much good: wider interest in science has been created amongst colonists, juster estimates of the country and its problems have been formed on the part of the visitors, and personal friendships and interchange of ideas between thinking men in South Africa and at home have arisen which cannot fail to have a beneficial influence on the social, political, and scientific relations between these colonies and the mother country. We may confidently look for. like results from the proposed visit of the Association to Canada in 1909 .

One is tempted to take advantage of the wide publicity given to words from this chair to speak at large in the cause of science, to insist upon the necessity for its wider inclusion in the education of our youth and the devotion of a larger measure of the public funds in aid of scientific research; to point to the supreme value of science as a means for the culture of those faculties which in man promote that knowledge which is power; and to show how dependent is the progress of a nation upon its scientific attainment.

But in recent years these truths have been prominently brought before the Association from this chair; they have been exhaustively demonstrated by Sir William Huggins from the chair of the Royal Society, and now a special guild ${ }^{1}$ exists for their enforcement upon the mind of the tation.

These considerations appear to warrant me in following the healthy custom of so many previous presidentsviz., of confining their remarks mainly to those departments of science with which the labours of their lives have been chiefly associated.

\section{The Science of Measurement.}

Lord Kelvin in $187 \mathrm{r}$ made a statement from the presidential chair of the Association at Edinburgh as follows: "Accurate and minute measurement seems to the nonscientific imagination a less lofty and dignified work than the looking for something new. But nearly all the grandest discoveries of science have been the reward of accurate measurement and patient, long-continued labour in the minute sifting of numerical results."

Besides the instances quoted by Lord Kelvin in support of that statement, we have perhaps as remarkable and typical an exemplification as any in Lord Rayleigh's long-continued work on the density of nitrogen which led him to the discovery of argon. We shall see presently that, true as Lord Kelvin's words are in regard to most ficld's of science, they are specially applicable as a guide in astronomy.

One of Clerk Maxwell's lectures in the Natural Philosophy Class at Marischall College, Aberdeen, when I was a student under him there, in the year 1859 , ran somewhat as follows :-

"A standard, as it is at present understood in English, is not a real standard at all; it is a rod of metal with lines ruled upon it to mark the yard, and it is kept somewhere in the House of Commons. If the House of Commons catches fire there may be an end of your standard. A copy of a standard can never be a real standard, because all the work of human hands is liable to error. Besides, will your sa-called standard remain of a constant length? It certainly will change by temperature, it probably will change by age (that is, by the re-

$$
1 \text { The British Scisnce Guild. }
$$

arrangement or settling down of its component molecules), and 1 am not sure if it does not change according to the azimuth in which it is used. At all events, you must see that it is a very impractical standard-impractical because, if, for example, any one of you went to Mars or Jupiter, and the people there asked you what was your standard of measure, you could not tell them, you could not reproduce it, and you would feel very foolish. Whereas, if you told any capable physicist in Mars or Jupiter that you used some natural invariable standard, such as the wavelength of the D-line of sodium vapour, he would be able to reproduce your yard or your inch, provided that you could tell him how many of such wave-lengths there were in your yard or your inch, and your standard would be available anywhere in the universe where sodium is found."

That was the whimsical way in which Clerk Maxwell used to impress great principles upon us. We all laughed before we understood; then some of us understood and remembered.

Now the scientific world has practically adopted Maxwell's form of natural standard. . It is true that it names that standard the metre; but that standard is not onemillionth of the earth's quadrant in length, as it was intended to be; it is merely a certain piece of metal approximately of that length.

It is true that the length of that piece of metal has been reproduced with more precision, and is known with higher accuracy in terms of many secondary standards, than is the length of any other standard in the world but it is, after all, liable to destruction and to possible secular change of length. For these reasons it cannot be scientifically described otherwise than as a piece of metal whose length at $0^{\circ} \mathrm{C}$. at the epoch A.D. 1906 is $=1,553,164$ times the wave-length of the red line of the spectrum of cadmium when the latter is observed in dry air at the temperature of $15^{\circ} \mathrm{C}$. of the normal hydrogen-scale at a pressure of $760 \mathrm{~mm}$. of mercury at $0^{\circ} \mathrm{C}$.

This determination, recently made by methods based on the interference of light-waves and carried out by MM. Perot and Fabry at the International Bureau of Weights and Measures, constitutes a real advance in scientific metrology. The result appears to be reliable within one ten-millionth part of the metre.

The length of the metre, in terms of the wave-length of the red line in the spectrum of cadmium, had been determined in 1892 by Michelson's method, with a mean result in almost exact accordance with that just quoted for the comparisons of 1906; but this agreement (within one part in ten millions) is due in some degree to chance, as the uncertainty of the earlier determination was probably ten times greater than the difference between the two independent results of 1892 and 1906 .

We owe to M. Guillaume, of the same International Bureau, the discovery of the remarkable properties of the alloys of nickel and steel, and from the point of view of exact measurement the specially valuable discovery of the properties of that alloy which we now call " invar." $\mathrm{He}$ has developed methods for treatment of wires made from this alloy which render more permanent the arrangement of their constituent molecules. Thus these wires, with their attached scales, may, for considerable periods of time and under circumstances of careful treatment, be regarded as nearly invariable standards. With proper precautions, we have found at the Cape of Good Hope that these wires can be used for the measurement of base lines of the highest geodetic precision with all the accuracy attainable by the older and most costly forms of apparatus : whilst with the new apparatus a base of 20 kilometres car be measured in less time and for less cost than one of a single kilometre with the older forms of measurement.

\section{The Great African Arc of Meridian.}

In connection with the progress of geodesy, time only permits me to say a few words about the Great African arc on the soth meridian, which it is a dream of my life to see completed.

The gap in the arc between the Limpopo and the previously executed triangulation in Rhodesia, which I reported to the Association at the Johannesburg meeting in 1905, has now been filled up. My own efforts, at 
6000 miles distance, had failed to obtain the necessary funds, but at Sir George Darwin's instance contributions were obtained from this Association, from the Royal Society and others, to the extent of half the estimated cost; the remaining half was met by the British South Africa Company. But for Darwin's happy intervention, which enabled me to secure the services of Captain Gordon and his party before the Transvaal Survey Organisation was entirely broken up, this serious gap in the great work would probably have long remained; for it is one thing to add to an existing undertaking of the kind, it is quite another to create a new organisation for a limited piece of work.

Since then Colonel (now Sir William) Morris has brought to a conclusion the reductions of the geodetic survey of the Transvaal and Orange River Colony, and his report is now in my hands for publication.

Dr. Rubin, under my direction, at the cost of the British South Africa Company, has carried the arc of meridian northwards to S. latitude $9^{\circ} 42^{\prime}$, so that we have now continuous triangulation from Cape L'Agulhas to within fifty miles of the southern end of Lake Tanganyika; that is to say, a continuous geodetic survey extending over twenty-five degrees of latitude.

It happens that, for the adjustment of the international boundary between the British Protectorate and the Congo Free State, a topographic survey is at the present moment being executed northward along the 30 th meridian from the northern border of German East Africa. A proposal on the part of the Royal Society, the Royal Geographical Society, the British Association, and the Royal Astronomical Society has been made to strengthen this work by carrying a geodetic triangulation through it along the 3oth Meridian, and thus adding $2 \frac{1}{2}^{\circ}$ to the African arc. These Societies together guarantee roool. towards the cost of the work, and ask for a like sum from Government to complete the estimated cost. The topographic survey will serve as the necessary reconnaissance. The topographic work will be completed by the end of January next, and the four following months offer the best season of the year for geodetic operations in these regions.

There is a staff of skilled officers and men on the spot sufficient to complete the work within the period mentioned, and the Intercolonial Council of the Transvaal and Orange River Colony most generously offers to lend the necessary geodetic instruments. The work will have to be done sooner or later, but if another expedition has to be organised for the purpose the work will then cost from twice to three times the present amount. One cannot therefore doubt that His Majesty's Government will take advantage of the present offer and opportunity to vote the small sum required. This done, we cannot doubt that the German Government will complete the chain along the eastern side of Lake Tanganyika, which lies entirely within their territory. Indeed, it is no secret that the Berlin Academy of Sciences has already prepared the necessary estimates with a view to recommending action on the part of its Government.

Captain Lyons, who is at the head of the survey of Egypt, assures me that preliminary operations towards carrying the arc southwards from Alexandria have been begun, and we have perfect confidence that in his energetic hands the work will be prosecuted with vigour. In any ease the completion of the African arc will rest largely in his hands. That arc, if ever my dream is realised, will extend from Cape L'Agulhas to Cairo, thence round the eastern shore of the Mediterranean and the islands of Greece, and there meet the triangulation of Greece itself, the latter being already connected with Struve's great arc, which terminates at the North Cape in lat. $70^{\circ} \mathrm{N}$ This will constitute an arc of $105^{\circ}$ in length-the longest arc of meridian that is measurable on the earth's surface.

\section{The Solar Parallax.}

Much progress has been made in the exact measurement of the great fundamental unit of astronomy-the solar parallax.

Early in $1877 \mathrm{I}$-ventured to predict ${ }^{1}$ that we should not arrive at any certainty as to the true value of the solar

1 " "The Determination of the Solar Parallax," the Observatory, vol. i. p. 280.

NO. I970, VOL. 76$]$ parallax from observations of transits of 'Venus, but that the modern heliometer applied to the measurement of angular distances between stars and the star-like images of minor planets would yield results of far higher precision.

The results of the observations of the minor planets Iris, Victoria, and Sappho at their favourable oppositions in the years 1888 and 1889 , which were made with the cooperation of the chief heliometer and meridian observatories, fully justified this prediction. ${ }^{1}$ The Sun's distance is now almost certainly known within one-thousandth part of its amount. The same series of observations also yielded a very trustworthy determination of the mass of the Moon.

The more recently discovered planet Eros, which in I9oo approached the Earth within one-third of the mean distance of the Sun, afforded a most unexpected and welcome opportunity for re-determining the solar parallax -an opportunity which was largely taken advantage of by the principal observatories of the northern hemisphere. Unfortunately the high northern declination of the planet prevented its obscrvation at the Cape and other southern observatories. So far as the results have been reduced and published ${ }^{2}$ they give an almost exact accordance with the value of the solar parallax derived from the helio meter observations of the minor planets, Iris, Victoria, and Sappho in 1888 and 1889.

But in I93I Eros will approach the Earth within onesixth part of the Sun's mean distance, and the fault will rest with astronomers of that day if they do not succeed in determining the solar parallax within one tenthousandth part of its amount.

To some of us who struggled so hard to arrive at a tenth part of this accuracy under the less favourable geometrical conditions that were available before the discovery of Eros, how enviable seems the opportunity!

And yet, if we come to think of it rightly, the true opportunity and the chief responsibility is ours, for now and not twenty years hence is the time to begin our preparation; now is the time to study the origin of those systematic errors which undoubtedly attach to some of our photographic processes; and then we ought to construct telescopes specially designed for the work. These telescopes should be applied to the charting of the stars near the path which Eros will describe at its opposition in 1931 , and the resulting star-coordinates derived from the plates photographed by the different telescopes should be rigorously inter-compared. Then, if all the telescopes give identical results for the star-places, we can be certain that they will record without systematic error the position of Eros. If they do not give identical results, the source of the errors must be traced.

The planet will describe such a long path in the sky during the opposition of $193 \mathrm{I}$ that it is already time to begin the meridian observations which are necessary to determine the places of the stars that are to be used for determining the constants of the plates. It is desirable, therefore, that some agreement should be come to with respect to selection of these reference-stars, in order that all the principal meridian observatories in the world may take part in observing them.

I venture to suggest that a Congress of Astronomers should assemble in 1908 to consider what steps should be taken with reference to the important opposition of Eros in 1931 .

\section{The Stellar Universe.}

And now to pass from consideration of the dimensions of our solar system to the study of the stars, or other suns, that surround us.

To the lay mind it is difficult to convey a due appreciation of the value and importance of star-catalogues of precision. As a rule such catalogues have nothing what ever to do with discovery in the ordinary sense of the word, for the existence of the stars which they contain is generally well known beforehand; and yet such catalogues are, in reality, by far the most valuable assets of astronomical research.

If it be desired to demarcate a boundary on the Earth's 1 "Annals of the Cape Observatory," vol. vi., part vi., p. 29.

2 Monthly Notices R.A.S., Hinks vol. 1xiv. p. 725 ;'Christie, vol. 1xvii. p. $3^{82}$. 
surface by astronomical methods, or to fix the position of any object in the heavens, it is to the accurate starcatalogue that we must refer for the necessary data. In that case the stars may be said to resemble the trigonometrical points of a survey, and we are only concerned to know from accurate catalogues their positions in the heavens at the epoch of observation. But in another and grander sense the stars are not mere landmarks, for each has its own apparent motion in the heavens which may be due in part to the absolute motion of the star itself in space, or in part to the motion of the solar system by which our point of view of surrounding stars is changed.

If we desire to determine these motions and to ascer tain something of the general conditions which produce them, if we would learn something of the dynamical conditions of the universe and something of the velocity and direction of our own solar system through space, it is to the accurate star catalogues of widely separated epochs that we must turn for a chief part of the requisite data.

The value of a star-catalogue of precision for present purposes of cosmic research varies as the square of its age and the square of its accuracy. We cannot alter the epoch of our observations, but we can increase their value fourfold by doubling their accuracy. Hence it is that many of our greater astronomers have devoted their lives chiefly to the accumulation of meridian observations of high precision, holding the view that to advance such precision is the most valuable service to science they could undertake, and comforted in their unselfish and laborious work only by the consciousness that they are preparing a solid foundation on which future astronomers may safely raise the superstructure of sound knowledge.

But since the extension of our knowledge of the system of the universe depends quite as much on past as on future research, it may be well, before determining upon a programme for the future, to consider briefly the record of meridian observation in the past for both hemispheres.

The Comparative State of Astronomy in the Northern and Southern Hemispheres.

It seems probable that the first express reference to southern constellations in known literature occurs in the Book of Job (ix. 9): "Which maketh Arcturus, Orion, and Pleiades, and the chambers of the south." Schiaparelli's strongly supported conjecture is that the expression "chambers of the south," taken with its context, signifies the brilliant stellar region from Canopus to $\alpha$ Centauri, which includes the Southern Cross and coincides with the most brilliant portion of the Milky Way.

About the year 750 B.c. (the probable date of the Book of Job) all these stars culminated at altitudes between $5^{\circ}$ and $16^{\circ}$ when viewed from the latitude of Judæa; but now, owing to precessional change, they can only be seen in a like striking manner from a latitude about $12^{\circ}$ further south.

The words of Dante have unquestionably originated the wonderful net of poetic fancy that has been woven about the asterism, which we now call Crux.

$$
\begin{aligned}
& \text { To the right hand I turned, and fixed my mind } \\
& \text { On the other pole at'entive, where I saw } \\
& \text { Four stars ne'er seen before save by the ken } \\
& \text { Of our first parents - Heaven of their rays } \\
& \text { Seemed joyous. O thou northern site! bereft } \\
& \text { Indeed, and widowed, since of these deprived. }
\end{aligned}
$$

All the commentators agree that Dante here referred to the stars of the Southern Cross.

Had Dante any imperfect knowledge of the existence of these stars, any tradition of their visibility from European latitudes in remote centuries, so that he might poetically term them the stars of our first parents?

Ptolemy catalogues them as $3 \pi, 32,33$, and 34 Centauri, and they are clearly marked on the Borgian globe described by Assemanus in $1 \% 90$. This globe was constructed by an Arabian in Egypt: it bears the date 622 Hegira, corresponding with A.D. 1225, and it is possible that Dante may have seen it.

Amerigo Vespucci, as he sailed in tropical seas, apparently recognised in what we now call Crux the four luminous stars of Dante; for in I 50 I he claimed to be the first European to have looked upon the stars of our first parents. His fellow-voyager, Andrea Corsali, wrote about NO. I 970, voL. 76$]$ the same time to Giuliano di Medici describing "the marvellous cross, the most glorious of all the celestial signs."

Thus much mysticism and romance have been woven about this constellation, with the result that exaggerated notions of its brilliancy have been formed, and to most persons its first appearance, when viewed in southern latitudes, is disappointing.

To those, however, who view it at upper culmination for the first time from a latitude a little south of the Canary Islands, and who at the same time make unconsciously a mental allowance for the absorption of light to which one is accustomed in the less clear skies of Northern Europe, the sight of the upright cross, standing as if fixed to the horizon, is a most impressive one. I at least found it so on my first voyage to the Cape of Good Hope. But how much more strongly must it have appealed to the mystic and superstitious minds of the early navigators as they entered the unexplored seas of the northern tropic! To them it must have appeared the revered image of the Cross pointing the way on their southward course-a symbol and sign of Hope and Faith on their entry to the unknown.

The first general knowledge of the brighter stars of the southern hemisphere we owe to Frederick de Hautman who commanded a fleet sent by the Dutch Government in I595 to the Far East for the purpose of exploring Japan. Hautman was wrecked and taken prisoner at Sumatra, and whilst there he studied the language of the natives and made observations of the positions and magnitudes of the fixed stars of the southern hemisphere. ${ }^{1}$

Our distinguished countryman Halley visited St. Helena in 1677 for the purpose of cataloguing the stars of the southern hemisphere. He selected a station now marked Halley's Mount on the Admiraity chart of the island. I have visited the site, and the foundations of the observatory still remain. Halley's observations were much hindered by cloud. On his return to England, Halley in 1679 published his "Catalogus Stellarum Australium," containing the magnitudes, latitudes, and longitudes of $34 \mathrm{I}$ stars, which, with the exception of seven, all belonged to the southern hemisphere.

But the first permanently valuable astronomical work in the southern hemisphere was done in $1751-2$ by the Abbé de Lacaille. He selected the Cape of Good Hope as the scene of his labours, because it was then perhaps the only spot in the world situated in a considerable southern latitude which an unprotected astronomer could visit in safety, and where the necessary aid of trained artisans to erect his observatory could be obtained. Lacaille received a cordial welcome at the hands of the Dutch governor Tulbagh: he erected his obserwatory in Cape Town, made a catalogue of nearly 10,000 stars, observed the opposition of Mars, and measured a short arc of meridian all in the course of a single year. Through his labours the Cape of Good Hope became the birthplace of astronony and geodesy in the southern hemisphere.

Bradley was laying the foundations of exact astronomy in the northern hemisphere at the time when Lacaille laboured at the Cape. But Bradley had superior instruments to those of Lacaille and much longer time at his disposal. Bradley's work is now the basis on which the fair superstructure of modern astronomy of precision rests. His labours were continued by his successors at Greenwich and by a long series of illustrious men like Piazzi, Groombridge, Bessel, Struve, and Argelander.. But in the southern hemisphere the history of astronomy is a blank for seventy years from the days of Lacaille.

We owe to the establishment of the Royal Observatory at the Cape by an Order in Council of 1820 the first successful step towards the foundation of astronomy of high precision in the southern hemisphere.

Time does not permit me to trace in detail the labours of astronomers in the southern hemisphere down to the present day; and this is the less necessary because in a recent Presidential Address to the South African Philosophical Society ${ }^{2}$ I have given in great part that history

1 The resulting catalogue of 304 stars is printed as an appendix to Hautman's "Vocabulary of the Malay Language," published at Amsterdam in 1603 .

2 Trans. South African Phil. Soc., vol, xiv., part 2. 
in considerable detail. But I have not there made adequate reference to the labours of Dr. Gould and Dr. Thome at Cordoba. To their labours, combined with the work done under Stone at the Cape, we owe the fact that for the epoch 1875 the meridian sidereal astronomy of the southern hemisphere is nearly as well provided for as that of the northern. The point $I$ wish to make is that the facts of exact sidereal astronomy in the southern hemisphere may be regarded as dating nearly a hundred years behind those of the northern hemisphere.

\section{The Constitution of the Universe.}

It was not until 1718, when Edmund Halley, afterwards Astronomer Royal of England, read a paper before the Royal Society, ${ }^{\prime}$ entitled "Considerations on the Change of the Latitudes of Some of the Principal Fixt Stars," that any definite facts were known about the constitution of the universe. In that paper Halley, who had been investigating the precession of the equinoxes, says: "But while I was upon this enquiry I was surprized to find the Latitudes of three of the principal Stars in heaven directly to contradict the supposed greater obliquity of the Ecliptick, which seems confirmed by the Latitudes of most of the rest."

This is the first mention in history of an observed change in the relative position of the so-called fixed stars -the first recognition of what we now call "proper motion."

Tobias Mayer, in 1760 , seems to have been the first to recognise that if our Sun, like other stars, has motion in space, that motion must produce apparent motion amongst the surrounding stars; for in a paper to the Göttingen Academy of Sciences he writes: "If the Sun, and with it the planets and the Earth which we inhabit, tended to move directly towards some point in the heavens, all the stars scattcred in that region would seem to gradually move apart from each other, whilst those in the opposite quarter would mutually approach each other. In the same manner one who walks in the forest sees the trees which are before him separate, and those that he leaves behind approach each other." No statement of the matter could be more clear; but Mayer, with the meagre data at his disposal, came to the conclusion that "the motions of the stars are not governed by the above or any other common law, but belong to the stars themselves."

Sir William Herschel, in $\mathrm{I} 78_{3}$, made the first attempt to apply, with any measure of success, Mayer's principle to a determination of the direction and amount of the sola motion in space. ${ }^{2} \mathrm{He}$ derived, as well as he could from existing data, the proper motions of fourteen stars, and arrived by estimation at the conclusion that the Sun's motion in space is nearly in the direction of the star $\lambda$ Herculis, and that 80 per cent. of the apparent motions of the fourteen stars in question could be assigned to this common origin.

This conclusion rests in reality upon a very slight basis, but the researches of subsequent astronomers show that it was an amazing accidental approach to truth-indeed, a closer approximation than Herschel's subsequent determinations of 1805 and 1806 , which rested on wider and better data. ${ }^{3}$

Consider for a moment the conditions of the problem. If all the stars except our Sun were at rest in space, then, in accordance with Mayer's statement, just quoted, all the stars would have apparent motions on great circles of the sphere away from the apex and towards the antapex of the solar motion. That is to say, if the position of each star of which the apparent motion is known was plottec on the surface of a sphere and a line with an arrow-head drawn through each star showing the direction of its motion on the sphere, then it should be possible to find a point on the sphere such that a great circle drawn from thic point through any star would coincide with the line of direction of that star's proper motion. The arrow-heads would all point to that intersection of the great circles which is the antapex of the solar motion, and the other point of intersection of the great circles would be the apex

1 Phil. Trans., 1718, p. 738

Ibid, , 1783 , p. 247

Ibid., 1805, p. 233 ; $18 c 6$, p. 205.

No. I970. VOL. 76$]$ that is to say, the direction of the Sun's motion in space.

But as the apparent stellar motions are small and only determinable with a considerable percentage of error, it would be impossible to find any point on the sphere such that every great circle passing through it and any particular star, would in every case be coincident with the observed direction of motion of that star.

Such discordances would, on our original assumption, be due to errors of observation, but in reality much larger discordances will occur, which are due to the fact that the other stars (or suns) have independent motions of their own in space. This at once creates a new difficulty, viz., that of defining an absolute locus in space. The human mind may exhaust itself in the effort, but it can never solve the problem. We can imagine, for example, the position of the Sun at any moment to be defined with reference to any number of surrounding stars, but by no effort of imagination can we devise means of defining the absolute position of a body in space without reference to surrounding material objects. If, therefore, the referring objects have unknown motions of their own, the rigour of the definition is lost.

What we call the observed proper motion of a star has three possible sources of origin :-

(I) The parallactic motion, or the effect of our Sun's motion through space, whereby our point of view of surrounding celestial objects is changed.

(2) The peculiar or particular motion of the star, i.e., its own absolute motion in space.

(3) That part of the observed or tabular motion which is due to inevitable error of observation.

In all discussions of the solar motion in space, from that of Herschel down till a recent date, it has been assumed that the peculiar motions of the stars are arranged at random, and may therefore be considered zero in the mean of a considerable number of them. It is then possible to find such a value for the Precession, and such a common apex for the solar motion as shall leave the residual peculiar motions of the stars under discussion to be in the mean=zero. That is to say, we refer the motion of the Sun in space to the centre of gravity of all the stars considered in the discussion, and regard that centre of gravity as immovable in space.

In order to proceed rigorously, and especially to determine the amount as well as the direction of the Sun's motion in space, we ought to know the parallax of every star employed in the discussion, as well as its proper motion. In the absence of such data it has been usual to start from some such assumption as the following: the stars of a particular magnitude are roughly at the same distance; those of different classes of magnitude may be derived from the hypothesis that on the average they have all equal absolute luminosity.

The assumption is not a legitimate one-

(I) Because of the extreme difference in the absolute uminosity of stars.

(2) Because it implies that the average absolute luminosity of stars is the same in all regions of space.

The investigation has been carried out by many successive astronomers on these lines with fairly accordant results as to the position of the solar apex, but with very unsatisfactory results as to the distances of the fixed stars. ${ }^{3}$ In order to judge how far the magnitude (or brightness) of a star is an index of its probable distance, we must have evidence from direct determinations of stellar parallax.

\section{Stellar Parallax.}

To extend exact measurement from our own solar system to that of other suns and other systems may be regarded as the supreme achievement of practical astronomy. So great are the difficulties of the problem, so minute the

1 Argelander, Mém. présentés à l'Acad. Imp. des Sciences St. Pétersbourg, tome iii. : Lundahl, Astron. Nachrichten, 398, 209; Argelander, Astron. Nachrichten. 398 zro; Otto Struve, Mém. Acad. des Sciences St. Péters bourg, vi ${ }^{e}$ série, Matb. et Phys., tome iii,, p. 17;.Galloway, Phil. Trans. 1847, p. 79 ; Mädler, Dorpat Observations, vol. xiv., and Ast. Nach., 566 2 13 Airy, Mem. R.A.S., vol. xxviii., p. 143; Dunlin, Mem. R.A.S., vol. xxxii., p. 19; Stone, Montbly Notices R.A.S., vol. xxiv. p. 36 ; De Ball, Inaugural Discertation, Bonn, 1877 ; Rancken, Astron. Nachrichten, 2482 r 49 ; Bischoff, Inaugural Discertation. Bonn, 1884; Ludwig Struve, Mćm Acad. St. Pétersbourg, viie série, tome xxxv., No. 3 . 
angles involved, that it is but in comparatively recent years that any approximate estimate could be formed of the true parallax of any fixed star. Bradley felt sure that if the star $\gamma$ Draconis had a parallax of $I^{\prime \prime}$ he would have detected it. Henderson by "the minute sifting of the numerical results" of his own meridian observations of $\alpha$ Centauri, made at the Cape of Good Hope in $1832-3$, first obtained certain evidence of the measurable parallax of any fixed star. He was favoured in this discovery by the fact that the object he selected happened to be, so far as we yet know, the nearest sun to our own. Shortly afterwards Struve obtained evidence of a measurable parallax for a Lyræ and Bessel for 6r Cygni. Astronomers hailed with delight this bursting of the constraints which our imperfect means imposed on research. But for the great purposes of cosmical astronomy what we are chiefly concerned to know is not what is the parallax of this or that particular star, but rather what is the average parallax of a star having a particular magnitude and proper motion. The prospect of even an ultimate approximate attainment of this knowledge seemed remote. The star $\alpha$ Lyræ is one of the brightest in the heavens; the star 6r Cygni one that had the largest proper motion known at the time; whilst $\alpha_{2}$ Centauri is not only a very bright star, but it has also a large proper motion. The parallaxes of these stars must therefore in all probability be large compared with the parallax of the average star; but yet to determine them with approximate accuracy long series of observations by the greatest astronomers and with the finest instruments of the day seemed necessary.

Subsequently various astronomers investigated the parallaxes of other stars having large proper motions, but it was only in $188 \mathrm{I}$, at the Cape of Good Hope, that general research on stellar parallax was instituted. ${ }^{1}$ Subsequently at Yale and at the Cape of Good Hope the work was continued on cosmical lines with larger and improved heliometers. ${ }^{2}$ By the introduction of the reversing prism and by ather practical refinements the possibilities of systematic error were eliminated, and the accidental errors of observaticn reduced within very small limits.

These researches brought to light the immense diversity in the absolute luminosity and velocity of motion of different stars. Take the following by way of example:-

Our nearest neighbour amongst the stars, $\alpha_{2}$ Centauri, has a parallax of $0^{\prime \prime} \cdot 76$, or is distant about $4^{\frac{1}{3}}$ light-years. Its mass is independently known to be almost exactly equal to that of our Sun; and its spectrum being also identical with that of our Sun, we may reasonably assume that it appears to us of the same magnitude as would our Sun if removed to the distance of $\alpha_{2}$ Centauri.

But the average star of the same apparent magnitude as $\alpha_{2}$ Centauri was found to have a parallax of only $\mathrm{o}^{\prime \prime} \cdot \mathrm{Io}$, so that either $\alpha_{2}$ Centauri or our Sun, if removed to a distance equal to that of the average fixed star of the first magnitude, would appear to us but little brighter than a star of the fifth magnitude.

Again, there is a star of only $8 \frac{1}{2}$ magnitude ${ }^{3}$ which has the remarkable annual proper motion of nearly $8 \frac{3}{4}$ seconds of arc-one of those so-called runaway stars-which moves with a velocity of 80 miles per second at right angles to the line of sight (we do not know with what velocity in the line of sight). It is at about the same distance from us as Sirius, but it emits but one ten-thousandth part of the light energy of that brilliant star. Sirius itself emits about thirty times the light-energy of our Sun, but it in turn sinks into insignificance when compared with the giant Canopus, which emits at least 10,000 times the lightenergy of our Sun.

Truly "one star differs from another star in glory." Proper motion rather than apparent brightness is the truer indication of a star's probable proximity to the Sun. Every star of considerable proper motion yet examined has proved to have a measurable parallax.

This fact at once suggests the idea, Why should not the apparent parallactic motions of the stars, as produced by the Sun's motion in space, be utilised as a means of determining stellar parallax?

1 Mem. R.A.S., vol. xlviii.

2 Annals of the Cane $\mathrm{Ob}$ ervatory, vol. viii., part ii., and Trans. Astron. Ohservatory of Yale University, vol. i.

3 Gould's Zones, Vh 243

$$
\text { No. 1970, vOL. 76] }
$$

Secular Parallactic Motion of Stars.

The strength of such determinations, unlike those made by the method of annual parallax, would grow with time. It is true that the process cannot be applied to the determination of the parallax of individual stars, because the peculiar motion of a particular star cannot be separated from that part of its apparent motion which is due to parallactic displacement. But what we specially want is not to ascertain the parallax of the individual star, but the mean parallax of a particular group or class of stars, and for this research the method is specially applicable, provided we may assume that the peculiar motions are distributed at random, so that they have no systematic tendency in any direction; in other words, that the centre of gravity of any extensive group of stars will remain fixed in space.

This assumption is, of course, but a working hypothesis, and one which from the paper on star-streaming communicated by Prof. Kapteyn of Groningen to the Johannesburg meeting of the Association two years ago we already know to be inexact. ${ }^{1}$ Kapteyn's results were quite recently confirmed in a remarkable way by Eddington, ${ }^{2}$ using independent material discussed by a new and elegant method. Both results showed that, at least for extensive parts of space, there are a nearly equal number of stars moving in exactly opposite directions. The assumption, then, that the mean of the peculiar motions is zero may, at least for these parts of space, be still regarded as a good working hypothesis.

Adopting an approximate position of the apex of the solar motion, Kapteyn resolved the observed proper motions of the Bradley stars into two components, viz., one in the plane of the great circle passing through the star and the apex, the other at right angles to that plane. ${ }^{3}$ The former component obviously includes the whole of the parallactic motion; the latter is independent of it, and is due entirely to the real motions of the stars themselves. From the former the mean parallactic motion of the group is derived, and from the combination of the two components, the relation of velocity of the Sun's motion to that of the mean velocity of the stars of the group.

As the distance of any group of stars found by the parallactic motion is expressed as a unit in terms of the Sun's yearly motion through space, the velocity of this motion is one of the fundamental quantities to be determined. If the mean parallax of any sufficiently extensive group or class of stars was known we should have at once means for a direct determination of the velocity of the Sun's motion in space; or if, on the other hand, we can by independent methods determine the Sun's velocity, then the mean parallax of any group of stars can be determined.

Determination of Stellar Motion in the Line of Sight.

Science owes to Sir William Huggins the application of Doppler's principle to the determination of the velocity of star-motion in the line of light. The method is now so well known, and such an admirable account of its theory and practical development was given by its distinguished inventor from this Chair at the Cardiff meeting in $189 \mathrm{r}$, that further mention of that part of the matter seems unnecessary.

The Velocity of the Sun's Motion in Space.

If by this method the velocities in the line of sight of a sufficient number of stars situated near the apex and antapex of the solar motion could be determined, so that in the mean it could be assumed that their peculiar motions would disappear, we have at once a direct determination of the required velocity of the Sun's motion.

The material for this determination is gradually accumulating, and indeed much of it, already accumulated, is not yet published. But even with the comparatively scant material available, it now seems almost certain that the true value of the Sun's velocity lies between 18 and 20 kilometres per second $;^{4}$ or, if we adopt the mean value, I9. kilometres per second, this would correspond almost

Rep. Brit. Asscc., roos, p. 257

Monthly Notices R.A.

Publications Astron, Lahoratory, Groningen, Nos, 7 and 9.

${ }_{4}$ Kapteyn, Ast. Nach., No. 3487 , p. 108; and Campbell, Astrophys. Journ 
exactly with a yearly motion of the Sun through space equal to four times the distance of the Sun from the Earth.

Thus the Sun's yearly motion being four times the Sun's distance, the parallactic motion of stars in which this motion is unforeshortened must be four times their parallax. How this number varies with the amount of foreshortening is of course readily calculated. The point is that from the mean parallactic motion of a group of stars we are now enabled to derive at once its mean parallax.

This research has been carricd out by Kapteyn for stars of different magnitudes. It leads to the result that the parallax of stars differing five magnitudes does not differ in the proportion of one to ten, as would follow from the supposition of equal luminosity of stars throughout the universe, but only in the proportion of about one to five. ${ }^{1}$

The same method cannot be applied to groups of stars of different proper motions, and it is only by a somewhat indirect proof, and by calling in the aid of such trustworthy results of direct parallax determination as we possess, that the variation of parallax with proper motion could be satisfactorily dealt with.

The Mean Parallaxes of Stars of Different Magnitude and Proper Motion.

As a final result Kapteyn derived an empirical formula giving the average parallax for stars of different spectral types, and of any given magnitude and proper motion. This formula was published at Groningen in 19or. ${ }^{2}$ Within the past few months the results of researches on stellar parallax, made under the direction of Dr. Elkin, at the Astronomical Observatory of Yale University, during the past thirteen years, ${ }^{3}$ have been published, and they afford a most crucial and entirely independent check on the soundness of Kapteyn's conclusions.

In considering the comparison between the more or less theoretical results of Kapteyn and the practical determinations of Yale, we have to remember that Kapteyn's tables refer only to the means of groups of a large number of stars having on the average a specified magnitude and proper motion, whilst the latter are direct determinations affected by the accidental errors of the separate determinations and by such uncertainty as attaches to the unknown parallaxes of the comparison stars-parallaxes which we have supplied from Kapteyn's general tables.

The Yale results consist of the determination of the parallax of 173 stars, of which only ten had been previously known to Kapteyn and had been utilised by him. Dividing these results into groups we get the following comparison :-

Comparison Groups arranged in order of Proper Motion.

\begin{tabular}{c|c|c|c|c|c}
\hline $\begin{array}{c}\text { No. of } \\
\text { stars }\end{array}$ & $\begin{array}{c}\text { Proper } \\
\text { Motion }\end{array}$ & Magnitude & \multicolumn{2}{|c|}{ Para'lax } & $\begin{array}{c}\text { Vale- } \\
\text { Kapteyn }\end{array}$ \\
& & Vale & Kapteyn & \\
\hline $\mathbf{2 1}$ & 0.14 & 3.8 & 0.028 & 0.026 & +0.002 \\
39 & 0.49 & 6.3 & 0.012 & 0.055 & -0.013 \\
45 & 0.59 & 6.7 & 0.068 & 0.060 & +0.008 \\
46 & 0.77 & 6.5 & 0.047 & 0.074 & -0.027 \\
$\mathbf{2 2}$ & 1.50 & 6.2 & 0.118 & 0.124 & -0.006 \\
\hline
\end{tabular}

Groups arranged in order of Magnitude.

\begin{tabular}{c|c|c|c|c|c|}
\hline $\begin{array}{c}\text { No. of } \\
\text { stars }\end{array}$ & $\begin{array}{c}\text { Proper } \\
\text { Motion }\end{array}$ & Magnitude & \multicolumn{2}{|c|}{ Parallax } & $\begin{array}{c}\text { Yale-- } \\
\text { Kapteyn }\end{array}$ \\
\hline & & Yale & Kafteyn & \\
\hline 10 & 0.61 & 0.8 & $0^{\prime \prime} 103$ & 0.110 & -0.007 \\
29 & 0.53 & 3.8 & 0.076 & 0.075 & +0.001 \\
33 & 0.63 & 5.6 & 0.064 & 0.070 & 0.006 \\
34 & 0.73 & 6.7 & 0.055 & 0.070 & -0.017 \\
31 & 0.68 & 7.6 & 0.025 & 0.061 & -0.036 \\
36 & 0.80 & 8.3 & 0.056 & 0.062 & -0.066 \\
\hline
\end{tabular}

1 Astron. Nachrichten, No. 3487 , table iii.; and Ast. Journ., p. 566.

2 Publications Astron. Laboratory, Groningen, No. 8, p. 24

3 Trans. Astron. Observatory of Yale Univ., vol. ii., part i.

NO. I970, voI. 76$]$

\begin{tabular}{|c|c|c|c|c|c|c|}
\hline \multirow{2}{*}{-} & \multirow{2}{*}{$\begin{array}{c}\text { No. } \\
\text { of } \\
\text { stars }\end{array}$} & \multirow{2}{*}{$\begin{array}{l}\text { Proper } \\
\text { Mution }\end{array}$} & \multirow{2}{*}{$\begin{array}{l}\text { Magni- } \\
\text { tude }\end{array}$} & \multicolumn{2}{|c|}{ Parallax } & \multirow{2}{*}{$\underset{\text { Kapteyn }}{\text { Yale- }}$} \\
\hline & & & & Yale & Kapteyn & \\
\hline $\begin{array}{l}\text { Spectral TypeI. } \\
,, \quad, \text { II. }\end{array}$ & $\begin{array}{l}\mathrm{I} 3 \\
8 \mathrm{I}\end{array}$ & $\begin{array}{l}0.42 \\
0.67\end{array}$ & $\begin{array}{l}4 \% \\
5 \% 3\end{array}$ & $\begin{array}{l}0.076 \\
0.067\end{array}$ & $\begin{array}{l}0.076 \\
0.074\end{array}$ & $\begin{array}{r}\text { ".0000 } \\
-0.007\end{array}$ \\
\hline
\end{tabular}

These results agree in a surprisingly satisfactory way, having regard to the comparatively small number of stars in each group and the great range of parallax which we know to exist amongst individual stars having the same magnitude and proper motion. In the mean perhaps the tabular parallaxes are in a minute degree too large, but we have unquestionable proof from this comparison that our knowledge of stellar distances now rests on a solid foundation.

\section{The Distribution of Varieties of Luminosity of Stars.}

But, besides the mean parallax of stars of a particular magnitude and proper motion, it is essential that we should know approximately what percentage of the stars of such a group have twice, three times, \&c., the mean parallax of the group, and what percentage only onehalf, one-third of that parallax, and so on. In principle, at least, this frequency-law may be obtained by means of the directly determined parallaxes. For the stars of which we have trustworthy determinations we can compare these true parallaxes with the mean parallax of stars having corresponding magnitude and proper motion, and this comparison will lead to a knowledge of the frequencylaw required. It is true that, owing to the scarcity of material at present available, the determination of the frequency-law is not so strong as may be desirable, but further improvement is simply a question of time and the augmentation of parallax-determination.

Adopting provisionally the frequency-law found in this way by Kapteyn, ${ }^{1}$ we can localise all the stars in space down to about the ninth magnitude.

Take, for example, the stars of magnitude 5.5 to 6.5 . There are about 4800 of these stars in the whole sky. According to Auwers-Bradley, about $9^{\frac{1}{2}}$ per cent. of these stars, or some 460 in all, have proper motions between $\mathrm{o}^{\prime \prime} \cdot 04$ and $\mathrm{o}^{\prime \prime} \cdot 05$. Now, according to Kapteyn's empiric formula, the satisfactory agreement of which with the Yale results has just been shown, the mean parallax of such stars is almost exactly o".or. Further, according to his frequency-law, 29 per cent. of the stars have parallaxes between the mean value and double the mean value 6 per cent. have parallaxes between twice and three times the mean value; $\mathrm{I}_{\frac{1}{2}}$ per cent, between three and four times the mean value. Therefore of our 460 stars 133 will have parallaxes between $\mathrm{o}^{\prime \prime} \cdot \mathrm{Or}$ and $\mathrm{o}^{\prime \prime} \cdot \mathrm{or}$, twentyeight between $\mathrm{o}^{\prime \prime} .02$ and $\mathrm{o}^{\prime \prime} \cdot 03$, seven between $\mathrm{o}^{\prime \prime} \cdot 03$ and $0^{\prime \prime} \cdot 04$, and so on.

Localising in the same way the stars of the sixth magnitude having other proper motions, and then treating the stars of the first magnitude, second magnitude, third magnitude, and so on to the ninth magnitude in the same way, we finally locate all these stars in space. $^{2}$

It is true we have not localised the individual stars, but we know approximately and within certain limits of magnitude the number of stars at each distance from the Sun.

Thus the apparent brightness and the distance being known we have the means of determining the light-energy or absolute luminosity of the stars, provided it can be assumed that lisht does not suffer any extinction in its passage through interstellar space.

On this assumption Kapteyn was led to the following results, viz., that within a sphere the radius of which is 560 light-years (a distance which corresponds with that of the average star of the ninth magnitude) there will be found :-

1 Publications Astron. L b., Groningen No. 8, p. 23. 2 Ibid., No. rr, table ii. 


\begin{tabular}{|c|c|c|c|c|c|c|}
\hline & $\operatorname{tar}$ & & $100, \infty 00$ & & $0, \infty 00$ & \\
\hline 26 & tars & ", & 10,000 & " & 1,000 & \\
\hline 1,300 & ,, & $"$ & 1,000 & ", & 100 & \\
\hline 22,000 & ", & ," & 100 & ," & 10 & ?. \\
\hline 40,000 & ," & , & 10 & ," & I & $\pi$ \\
\hline 0,000 & ," & ," & r & ", & 0.1 & \\
\hline 650,000 & , & ", & 0.1 & , & & \\
\hline
\end{tabular}

The Density of Stellar Distribution at Different Distances from our Sun.

Consider, lastly, the distribution of stellar density, that is, the number of stars contained in the unit of volume.

We cannot determine absolute star-density, because, for example, some of the stars which we know from their measured parallaxes to be comparatively near to us are in themselves so little luminous that if removed to even a few light-years greater distance they would appear fainter than the ninth magnitude, and so fall below the magnitude at which our data at present stop.

But if we assume that intrinsically faint and bright stars are distributed in the same proportion in space, it will be evident that the comparative richness of stars in any part of the system will be the same as the comparative richness of the same part of the system in stars of a particular luminosity. Therefore, as we have already found the arrangement in space of the stars of different degrees of luminosity, and consequently their number at different distances from the Sun, we must also be able to determine their relative density for these different distances.

Kapteyn finds in this way that, starting from the Sun, the star-density (i.e., the number of stars per unit volume of space) is pretty constant until we reach a distance of some 200 light-years. Thence the density gradually diminishes until, at about 2500 light-years, it is only about one-fifth of the density in the neighbourhood of the Sun. ${ }^{1}$ This conclusion must, however, be regarded as uncertain until we have by independent means been enabled to estimate the absorption of light in its course through interstellar space, and obtained proof that the ratio of intrinsically faint to bright stars is constant throughout the universe.

Thus far Kapteyn's researches deal with the stellar universe as a whole; the results, therefore, represent only the mean conditions of the system. The further development of our knowledge demands a like study applied to the several portions of the universe separately. This will require much more extensive material than we at present possess.

As a first further approximation the investigation will have to be applied separately to the Milky Way and the parts of the sky of higher galactic latitude. The velocity and direction of the Sun's motion in space may certainly be treated as constants for many centuries to come, and these constants may be separately determined from groups of stars of various regions, various magnitudes, various proper motions, and various spectral types. If these constants as thus separately determined are different, the differences which are not attributable to errors of observation must be due to a common velocity or direction of motion of the group or class of star to which the Sun's velocity or direction is referred. Thus, for example, the Sun's velocity as determined by spectroscopic observations of motion in the line of sight appears to be sensibly smaller than that derived from fainter stars. The explanation appears to be that certain of the brighter stars form part of a cluster or group of which the Sun is a member, and these stars tend to some extent to travel together. For these researches the existing material, especially that of the determination of velocities in the line of sight, is far too scanty.

Kapteyn has found that stars the proper motions of which exceed $\mathrm{o}^{\prime \prime} .05$ are not more numerous in the Milky Way than in other parts of the sky; ${ }^{2}$ in other words, if only the stars having proper motions of $\mathrm{o}^{\prime \prime}: 05$ or upwards were mapped there would be no aggregation of stars showing the existence of a Milky Way.

The proper motions of stars of the second spectral type are, as a rule, considerably larger than those of the first

1 Publications Astron. I ab.. Groningen, No. 2 .

2 Ver!, Kn. Akad. Amster'am, January, 1893.

No. I970, VOL. 76$]$ type; but Kapteyn comes to the conclusion that this difference does not mean a real difference of velocity, but only that the second-type stars have a smaller luminosity, the mean difference between the two types amounting to $2 \frac{\frac{1}{2}}{2}$ magnitudes. ${ }^{1}$

The Future Course of Research.

In the last Address delivered from this Chair on an astronomical subject, Sir William Huggins, in 1891, dealt so fully with the chemistry of the stars that it seemed fitting on the present occasion to consider more especially the problem of their motion and distribution in space, as it is in this direction that the most striking advances in our knowledge have recently been made. It is true that since I89I great advances have also been made in our detailed knowledge of the chemistry of the Sun and stars. The methods of astro-spectrography have been greatly improved, the precision of the determination of motion in the line of sight greatly enhanced, and many discoveries made of those close double stars, ordinarily termed spectroscopic doubles, the study of which seems destined to throw illustrative light upon the probable history of the development of systems from the original nebular condition to that of more permanent systems.

But the limitations of available time prevent me from entering more fully into this tempting field, more especially as it seems desirable, in the light of what has been said, to indicate the directions in which some of the astronomical work of the future may be most properly systematised. There are two aspects from which this question may be viewed. The first is the more or less immediate extension of knowledge or discovery; the second the fulfilment of our duty, as astronomers, to future generations. These two aspects should never be entirely separated. The first, as it opens out new vistas of research and improved methods of work, must often serve as a guide to the objects of the second. But the second is to the astronomer the supreme duty, viz., to secure for future generations those data the value of which grows by time.

As the result of the Congress of Astronomers held at Paris in 1887 some sixteen of the principal observatories in the world are engaged, as is well known, in the laborious task, not only of photographing the heavens, but of measuring these photographs and publishing the relative positions of the stars on the plates down to the eleventh magnitude. A century hence this great work will have to be repeated, and then, if we of the present day have done our duty thoroughly, our successors will have the data for an infinitely more complete and thorough discussion of the motions of the sidereal system than any that can be attempted to-day. But there is still needed the accurate meridian observation of some eight or ten stars on each photographic plate, so as to permit the conversion of the reiative star-places on the plate into absolute star-places in the heavens. It is true that some of the astronomers have already made these observations for the reference stars of the zones which they have undertaken. But this seems to be hardly enough. In order to coordinate these zones, as well as to give an accuracy to the absolute positions of the reference stars corresponding with that of the relative positions, it is desirable that this should be done for all the reference stars in the sky by several observatories. The observations of well-distributed stars by Kustner at Bonn present an admirable instance of the manner in which the work should be done. Several observatories in each hemisphere should devote themselves to this work, employing the same or other equally efficient means for the elimination of sources of systematic error depending on magnitude, \&c., and it is of far more importance that we should have, sav, two or three observations of each star at three different observatories than two or three times as many observations of each star made at a single observatory.

The southern cannot boast of a richness of instrumental and personal equipment comparable with that of the northern hemisphere, and consequently one welcomes with enthusiasm the proposal on the part of the Carnegie Institute to establish a meridian observatory in a suitable 1 Ihid., April, rog̣a. 
situation in the southern hemisphere. Such an observatory, energetically worked, with due attention to all necessary precautions for the exclusion of systematic errors, would conduce more than anything else to remedy in some degree that want of balance of astronomical effort in the two hemispheres to which allusion has already been made. But in designing the programme of the work it should be borne in mind that the proper duty of the meridian instrument in the present day is no longer to determine the positions of all stars down to a given order of magnitude, but to determine the positions of stars which are geometrically best situated and of the most suitable magnitude for measurement on photographic plates, and to connect these with the fundamental stars. For this purpose the working list of such an observatory should include only the fundamental stars and the stars which have been used as reference stars for the photographic plates.

Such a task undertaken by the Carnegie Observatory, by the Cape, and if possible by another observatory in the southern hemisphere, and by three observatories in the northern, would be regarded by astronomers of the future as the most valuable contribution that could be made to astronomy of the present day. Taken in conjunction with the astrographic survey of the heavens now so far advanced, it is an opportunity that if lost can never be made good; a work that would grow in value year by year as time rolls on, and one that would ever be remembered with gratitude by the astronomers of the future.

But for the solution of the riddle of the universe much more is required. Besides the proper motions, which would be derived from the data just described, we need for an ideal solution to know the velocity in the line of sight, the parallax, the magnitude, and the spectrumtype of every star.

The broad distinction between these latter data and the determination of proper motion is this, that whereas the observations for proper motion increase in value as the square of their age, those for velocity in the line of sight, parallax, magnitude, and type of spectrum may, for the broader purposes of cosmical research, be made at any time without loss of value. We should therefore be most careful not to sacrifice the interests of the future by immediate neglect of the former for the latter lines of research. The point is that those observatories which undertake this meridian work should set about it with the least possible delay, and prosecute the programme to the end with all possible zeal. Three observatories in each hemisphere should be sufficient; the quality of the work should be of the best, and quality should not be sacrificed for speed of work.

But the sole prosecution of routine labour, however high the ultimate object, would hardly be a healthy condition for the astronomy of the immediate future. The sense of progress is essential to healtby growth, the desire to know must in some measure be gratified. We have to test the work that we have done in order to be sure that we are working on the right lines, and new facts, new discoveries, are the best incentives to work.

For these reasons Kapteyn, in consultation with his colleagues in different parts of the world, has proposed a scheme of research which is designed to afford within a comparatively limited time a great augmentation of our knowledge. The principle on which his programme is based is that adequate data as to the proper motions, parallaxes, magnitudes, and the type of spectrum of stars situated in limited but symmetrically distributed areas of the sky, will suffice to determine many of the broader facts of the constitution of the universe. His proposals and methods are known to astronomers and need not therefore be here repeated. In all respects save one these proposals are practical and adequate, and the required cooperation may be said to be already secured-the exception is that of the determination of motion in the line of sight.

All present experience goes to show that there is no known satisfactory method of determining radial velocity of stars by wholesale methods, but that such velocities must be determined star by star. For the fainter stars huge telescopes and spectroscopes of comparatively low dispersion must be employed. On this account there is great need in both hemispheres of a huge reflecting telescope-six to eight feet in aperture-devoted almost exclusively to this research. Such a telescope is already in preparation at Mount Wilson, in America, for use in the northern hemisphere. Let us hope that Prof. Pickering's appeal for a large reflector to be mounted in the southern hemisphere will meet with an adequate response, and that it will be devoted there to this all-important work.

\section{Conclusion.}

The ancient philosophers were confident in the adequacy of their intellectual powers alone to determine the laws of human thought and regulate the actions of their fellow men, and they did not hesitate to employ the same unsupported means for the solution of the riddle of the universe. Every school of philosophy was agreed that some object which they could see was a fixed centre of the universe, and the battle was fought as to what that centre was. The absence of facts, their entire ignorance of methods of exact measurement, did not daunt them, and the question furnished them a subject of dispute and fruitless occupation for twenty-five centuries.

But astronomers now recognise that Bradley's meridian observations at Greenwich, made only i5o years ago, have contributed more to the advancement of sidereal astronomy than all the speculations of preceding centuries. They have learned the lesson that human knowledge in the slowly developing phenomena of sidereal astronomy must be content to progress by the accumulating labours of successive generations of men; that progress will be measured for generations yet to come more by the amount of honest, well-directed, and systematically discussed observation than by the most brilliant speculation ; and that, in observation, concentrated systematic effort on a special thoughtfully selected problem will be of more avail than the most brilliant but disconnected work.

By these means we shall learn more and more of the wonders that surround us, and recognise our limitations when measurement and facts fail us.

Huggins's spectroscope has shown that many nebula are not stars at all; that many well-condensed nebulæ, as well as vast patches of nebulous light in the sky, are but inchoate masses of luminous gas. Evidence upon evidence has accumulated to show that such nebulæ consist of the matter out of which stars (i.e.; suns) have been and are being evolved. The different types of star spectra form such a complete and gradual sequence (from simple spectra resembling those of nebulæ onwards through types of gradually increasing complexity) as to suggest that we have before us, written in the cryptograms of these spectra, the complete story of the evolution of suns from the inchoate nebula onwards to the most active sun (like our own), and then downward to the almost heatless and invisible ball. The period during which human life has existed on our globe is probably too short-even if our first parents had begun the work - to afford observational proof of such a cycle of change in any particular star; but the fact of such evolution, with the evidence before us, can hardly be doubted. I most fully believe that, when the modifications of terrestrial spectra under sufficiently varied conditions of temperature, pressure, and environment have been further studied, this conclusion will be greatly strengthened. But in this study we must have regard also to the spectra of the stars themselves. The stars are the crucibles of the Creator. There we see matter under conditions of temperature and pressure and environment, the variety of which we cannot hope to emulate in our laboratories, and on a scale of magnitude beside which the proportion of our greatest experiment is less than that of the drop to the ocean. The spectroscopic astronomer has to thank the physicist and the chenist for the foundation of his science, but the time is coming-we almost see it nowwhen the astronomer will repay the debt by wide-reaching contributions to the very fundamenta of chemical science.

By patient, long-continued labour in the minute sifting of numerical results, the grand discovery has been made that a great part of space, so far as we have visible knowledge of it, is occupied by two maiestic streams of stars travelling in opposite directions. Accurate and 
minute measurement has given us some certain knowledge as to the distances of the stars within a certain limited portion of space, and in the cryptograms of their spectra has been deciphered the amazing truth that the stars of both streams are alike in design, alike in chemical constitution, and alike in process of development.

But whence have come the two vast streams of matter out of which have been evolved these stars that now move through space in such majestic procession?

The hundreds of millions of stars that comprise these streams, are they the sole ponderable occupants of space? However vast may be the system to which they belong, that system itself is but a speck in illimitable space; may it not be but one of millions of such systems that pervade the infinite?

We do not know.

"Canst thou by searching find out God? canst thou find out the Almighty unto perfection?"

\section{Section A.
Mathematics and physics.}

Opening Adpress by Prof. A. E. H. Love, M.A., D.Sc., F.R.S., President of the Section.

I pPopose to use the opportunity afforded by this Address to explain a dynamical theory of the shape of thy earth, or, in other words, of the origin of continents And oceans.

The theory which has for more than a century been associated with the phrase "the figure of the earth" is the theory of the shape of the surface of the ocean. Apart from waves and currents, this surface is determined by the condition that there is no up and down upon it. This condition does not mean that the surface is everywhere at the same distance from the centre of the earth, or even that it is everywhere convex, but that a body moving upon it neither rises against, nor falls in the direction of, gravity (modified by the rotation). A surface which has this character is called an equipotential surface, and the surface of the ocean coincides with part of an equipotential surface under gravity moditied by the rotation. This particular equipotential surface runs underground beneath the continents. It is named the " geoid." The height of a place above sea-level means its height abcve the geoid. If we knew the distribution of density of the matter within the earth it would be a mathematical problem to determine the form of the geoid. As we do not know this distribution we have recourse to an indirect means of investigation, and the chief instrument of research is the pendulum. The time of vibration of a pendulum varies with the place where it is swung, and from the observed times we deduce the values of gravity at the various places, and it was shown many years ago by Stokes that the shape of the geoid can be inferred from the variation of gravity over the surface.

The question to which I wish to invite your attention is a different one. If the ocean could be dried up, the earth would still have a shape. What shape would it be? Why should the earth have that shape rather than some other? In order to describe the shape we may imagine that we try to make a model of it. If we could begin with a model of the geoid we should have to attach additional material over the parts representing land and to remove some material over the parts representing sea. Our model would have to be as big as a battleship if the elevations and depressions were to be as much as 3 or 4 inches. In thinking out the construction of such a model we could not fail to be impressed by certain general features of the distribution of continent and ocean, and we may examine a map to discover such features. Fig. $I$ is a rough map of the world drawn in such a way that to every degree of latitude or of longitude there corresponds the same distance on the map. Certain very prominent features have often been remarked: the tapering of America and Africa towards the south, the disproportion between the land areas of the northern and southern hemispheres, the excess of the oceanic area above the continental area, which occupies but little more than one-quarter of the surface; the wide extent of the Pacific Ocean, which with the adjoining parts of the Southern Orean covers nearly. two-fifths of the surface. Another prominent feature is the antipodal position of continent and ocean. South America south of an irregular line which runs from a point near Lake Titicaca to Buenos Ayres is antipodal to a portion of Asia which lies in an irregular triangle with corners near Bangkok, Kiaochau, and Lake Baikal; but no other considerable parts of the continental system have continental antipodes. The Antarctic continent is antipodal to the Arctic Ocean, Australia is antipodal to the central Atlantic, and so on. Another notable feature is the skew position of South America to the east of North America; South America lies to the east of the meridian $85^{\circ}$ west of Greenwich; most of North America lies to the west of it. But although we may observe prominent general features of the distribution, we should find it far from easy to attribute to the form of our imaginary model any-

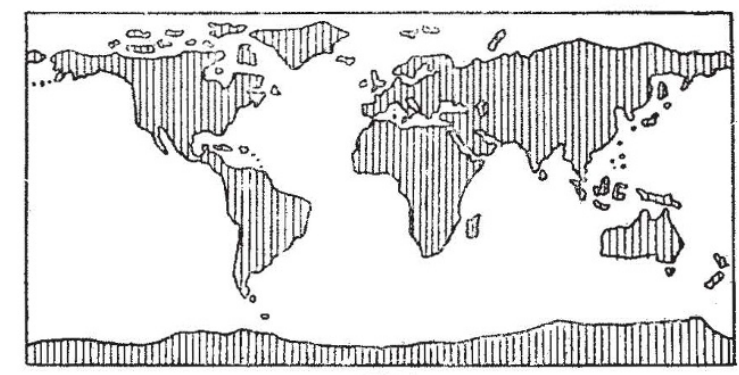

Fig.l.

thing that could be called a regular geometrical figure. When we begin to think about the removal of material from the parts of the model which are to represent oceans and seas, we require a map which gives information about the depth of the sea in different places. Around all the coasts there is a margin of not very deep water. If some part of the sea could be dried up, so that more land was exposed around all the coasts, the area of the surface of the sea would be diminished; and it is known that the depth of water that would have to be removed in order to make the area of the sea just half the total area is about 1400 fathoms. The contour-line at this depth would divide the surface into two regions of approximately equal area-the continental region and the oceanic region. Fig. 2 represents the contour-line at 1400 fathoms, or the

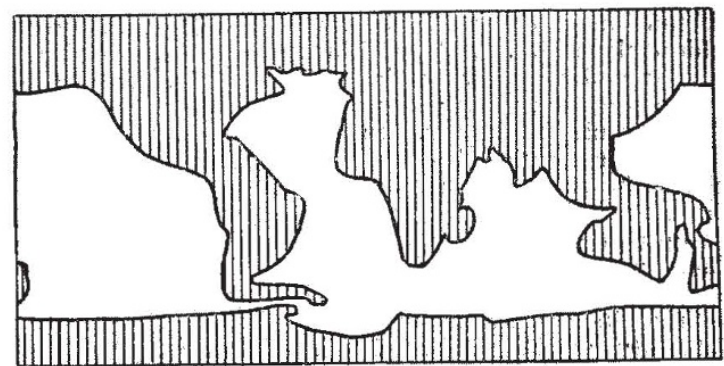

Fig. 2.

line of separation of the continental and oceanic regions. The continental region is shaded. In drawing this map I have omitted a number of small islands, and I have also omitted a few enclosed patches of deep water. Two of these are in the Mediterranean, one in the Arctic Ocean, and others are in the Gulf of Mexico and the Caribbean Sea. The Red Sea, the Mediterranean, and the Arctic Ocean belong to the continental region, and so do the Gulf of Mexico and the Caribbean Sea. At this depth Asia and North America are joined across Behring's Strait, and Europe is joined to North America across the British Isles, Iceland, and Greenland; Australia is joined to Asia through Borneo and New Guinea, and the Austral asian continental region nearly reaches the Antarctic region by way of New Zealand. At this depth also South America does not taper to the south, but 
spreads out, and is separated from the Antarctic region by a very narrow channel. By going down to great depths our problem is very much simplified. We find that the surface of the earth can be divided into continental and oceanic regions of approximately equal area by a curve which approaches a regular geometrical shape. By smoothing away the irregularities we obtain the curve shown in Fig. 3, which exhibits the surface as divided up into a continuous continental region and two oceanic regionsthe basin of the Pacific Ocean and the basin of the Atlantic and Indian Oceans. We may take our problem to be this : to account on dynamical grounds for the separation of the surface into a continental region and two oceanic regions which are approximately of this shape.

The key of the problem was put into our hands four years ago by Jeans in his theory of gravitational instability. If there are any differences of density in different parts of a gravitating body, the denser parts attract with a greater force than the rarer parts, and thus more and more of the mass tends to be drawn towards the parts where the densily is in excess, and away from the parts where it is in defect. In every gravitating system there is a tendency to instability. In a body of planetary dimensions this tendency, if it were not checked, would result in a concentration of the mass either towards the centre or towards some other part. But concentration of the mass means compression of the material, and it cannot proceed very far without being checked by the resistance which the material offers to compression. There ensues a sort of competition between two agencies: gravitation, making for instability, and the elastic resistance to com-

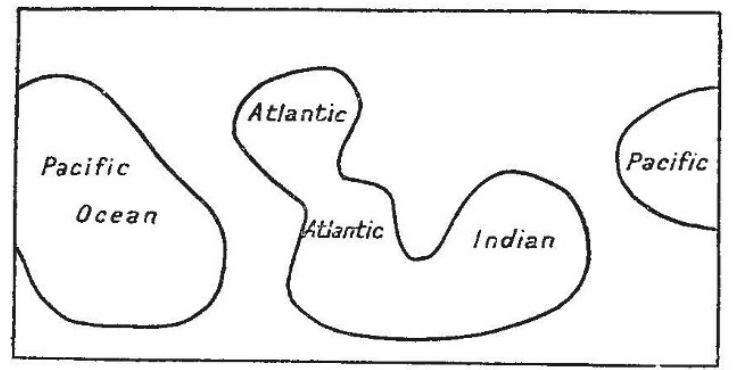

Fig.3.

pression, making for stability. Such competing agencies are familiar in other questions concerning the stability of deformable bodies. A long thin bar set up on end tends to bend under its own weight. A steel knitting-needle a foot long can stand up; a piece of thin paper of the same length would bend over. In order that a body may be stable in an assigned configuration there must be some relation between the forces which make for instability, the size of the body, and the resistance which it offers to changes of size and shape. In the case of a gravitating planet we may inquire how small its resistance to compression must be in order that it may be unstable, and, further, in respect of what types of displacement the instability would manifest itself. If we assign the constitution of the planct, the inquiry becomes a definite mathematical problem. The greatest difficulty in the problem arises from the enormous stresses which are developed within such a body as the earth by the mutual gravitation of its parts. The earth is in a state which is described technically as a state of "initial stress." In the ordinary theory of the mechanics of deformable bodies a body is taken to be strained or deformed when there is any stress in it, and the strain is taken to be porportional to the stress. This method amounts to measuring the strain or deformation from an ideal state of zero stress. If the ideal state is unattainable without rupture or permanent set or overstrain, the body is in a state of initial stress. The commonest example is a golf ball made of india-rubber tightly wound at a high tension. Now the problem of gravitational instability can be solved for a planet of the size of the earth on the suppositions that the density is uniform and the initial stress is hydrostatic pressure. If the resistance to compression is sufficiently

No. I970, VOI. 76$]$ small the body is unstable, both as regards concentration of mass towards the centre and as regards displacements by which the density is increased in one hemisphere and diminished in the other. A planetary body of sufficiently small resistance to compression could not exist in the form of a homogeneous sphere. It could exist in a state in which the surface is very nearly spherical, and the mass is arranged in a continuous series of nearly spherical thin sheets, each of constant density; but these sheets would not be concentric. They would be crowded together towards one side and spaced out on the opposite side somewhat in the manner shown in Fig. 4. The effect would be a displacement of the centre of gravity away from the centre of figure towards the side where the sheets are crowded together. How small must the resistance to compression be in order that, this state may be assumed by the body instead of a homogeneous state? The answer is that, if the body has the same size and mass as the earth, the material must be as compressible as granite. Granite, as we know it at the earth's surface, is not a typically compressible material. A cube of granite ro feet every way could be compressed from its volume of 1000 cubic feet to a volume of 999 cubic feet by pressure applied to every part of its surface; but according to the recent measurements of Adams and Coker the pressure would have to be rather more than two tons per square inch. A homogeneous sphere of the same size and mass as the earth, made of a material as nearly incompressible as granite, could not exist; it would be gravitationally unstable. The body would take up some such state of

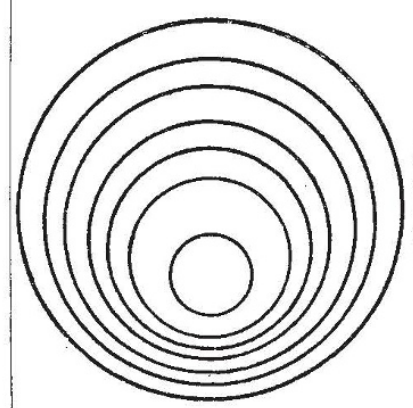

Fig.4.

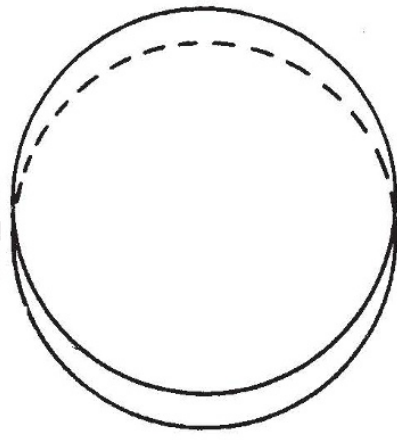

Fig.5. aggregation as that illustrated in Fig. 4, and its centre of gravity would have an eccentric position.

Now how would an ocean rest on a gravitating sphere of which the centre of gravity does not coincide with the centre of figure? Its surface would be a sphere with its centre at the centre of gravity (Fig. 5). The oceanic region would be on one side of the sphere and the continental region on the other side. It was pointed out many years ago by Pratt that the existence of the Pacific Ocean shows that the centre of gravity of the earth does not coincide with the centre of figure. There is no necessity to invoke some great catastrophe to account for the existence of the Pacific Ocean, or to think of it as a kind of pit or scar on the surface of the earth. The Pacific Ocean resembles nothing so much as a drop of water adhering to a greasy shot. The force that keeps the drop in position is surface tension. The force that keeps the Pacific Ocean on one side of the earth is gravity, directed more towards the centre of gravity than the centre of figure. An adequate cause for the eccentric position of the centre of gravity is found in the necessary state of aggregation which the earth must have had if at one time it was as compressible as granite. The theory of gravitational instability accounts for the existence of the Pacific Ocean.

But we can go much further than this in the direction of accounting for the continental and oceanic regions. We keep in mind the eccentric position of the centre of gravity, and try to discover the effect of rotation upon a planet of which the centre of gravity does not coincide with the centre of figure. The shape of a rotating planet must be nearly an oblate spheroid; but the figure of the ocean would, owing to its greater mobility, be rather more 
protuberarit at the equator than the figure of the planet on which it rests. The primary effect of the rotation of the earth upon the distribution of continent and ocean is to draw the ocean towards the equator, so as to tend to expose the Arctic and Antarctic regions. We have seen that both Arctic and Antarctic are parts of the continental region. But there is an important secondary effect. Under the influence of the rotation the parts of greater density tend to recede further from the axis than the parts of less density. If the density is greater in one hemispheroid than in the other, so that the position of the centre of gravity is eccentric, the effect must be to produce a sort of furrowed surface; and the amount of elevation and depression so produced can be described by an exact mathematical formula. It has been proved that this formula is a sort of expression which mathematicians name a spherical harmonic of the third degree.

The shape of the earth is also influenced by another circumstance. We know that at one time the moon was much nearer to the earth than it is now, and that the two bodies once rotated about their common centre of gravity almost as a single rigid system. The month was nearly as short as the day, and the moon was nearly fixed in the sky. The earth must then have been drawn out towards the moon, so that its surface was more nearly an ellipsoid with three unequal axes than it is now. The primary effect of the ellipsoidal condition upon the distribution of continent and ocean would be to raise the surface above the ocean near the opposite extremities of the greatest diameter of the equator. But, again, owing to the eccentric position of the centre of gravity, there would be an important secondary effect. The gravitational attraction of an ellipsoid differs from that of a sphere, and it may be represented as the attraction of a sphere together with an additional attraction. If the density was greater in one hemi-ellipsoid than in the other, the additional attraction would produce a greater effect in the parts where the density was in excess, and the result, just as in the case of rotation, would be a furrowing of the surface. It has been proved that the formula for this furrowing also is expressed by a spherical harmonic of the third degree.

We are brought to the theory of spherical harmonics and the spherical harmonic analysis. Spherical harmonics are certain quantities which vary in a regular fashion over the surface of a sphere, becoming positive in some parts and negative in others. I spoke just now of making a model of a nearly spherical surface by removing material from some parts and heaping it up on others. Spherical harmonics specify standard patterns of deformation of spheres. For instance, we might remove material over one hemisphere down to the surface of an equal but not concentric sphere (cf. Fig. 5) and heap up the material over the other hemisphere. We should produce a sphere equal to the original but in a new position. The formula for the thickness of the material removed or added is a spherical harmonic of the first degree. It specifies the simplest standard pattern of deformation. Again, we might remove material from some parts of our model and heap it up on other parts so as to convert the sphere into an ellipsoid. The formula for the thickness of that which is removed or added is a spherical harmonic of the second degree. Deformation of a sphere into an ellipsoid is the second standard pattern of deformation. The mathematical method of determining the appropriate series of standard patterns is the theory of spherical harmonics. Its importance arises from the result that any pattern whatever can be reached by first making the deformation according to the first pattern; then going on to make the deformation according to the second pattern, and so on. If we begin with a pattern, for instance the shape of the earth, which is not a standard pattern, we can find out how great a deformation of each standard pattern must be made in order to reproduce the prescribed pattern. The method of doing this is the method of spherical harmonic analysis. Except in very simple cases the application of it involves rather tedious computations. With much kind assistance and encouragement from Prof. Turner, I made a rough spherical harmonic analysis of the earth's surface. I divided the surface into 2592 small areas, rather smaller on the average than Great Britain. gave them the value $+I$, or one unit of elevation, if they are above the sea, and the value -I, or one unit of depression, if they are below the I400-fathom line. To the intermediate areas I gave the value 0 . The distribution of the numbers over the surface was analysed for spherical harmonics of the first, second, and third degrees.

Any spherical harmonic of the first degree gives us a division of the surface into two hemispheres-one elevated, the other depressed. The spherical harmonic analysis informs us as to the position of the great circle which separates the two hemispheres, and also as to the ratio of the maximum elevation of this pattern to the maximum elevation of any other pattern. The central region of greatest elevation of this pattern is found to be in the neighbourhood of the Crimea, and the region of elevation

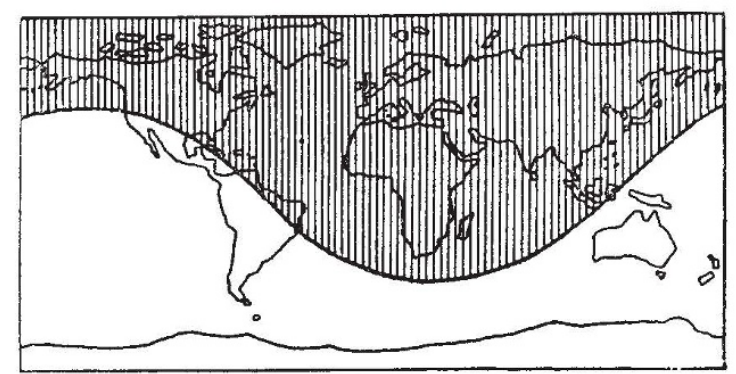

Fig.6.

contains the Arctic Ocean and the northern and central parts of the Atlantic, Europe, Africa, Asia, most of North America, and a small part of South America. When the surface is mapped on a rectangle in the same way as before, "the chart of the harmonic is that shown in Fig 6. . The actual disproportion between the amounts of continental area in the northern and southern hemispheres is associated with the result that the central region of elevation, as given by the analysis, is about $45^{\circ}$ north of the equator; and the extension of the Yacific. Ocean and adjoining Southern Ocean to much higher southern than northern latitudes is associated with the corresponding position of the central region of greatest depression about $45^{\circ}$ south of the equator. In regard to harmonics of the second degree, the spherical harmonic analysis informs us as to the ellipticity of the equator and the obliquity of

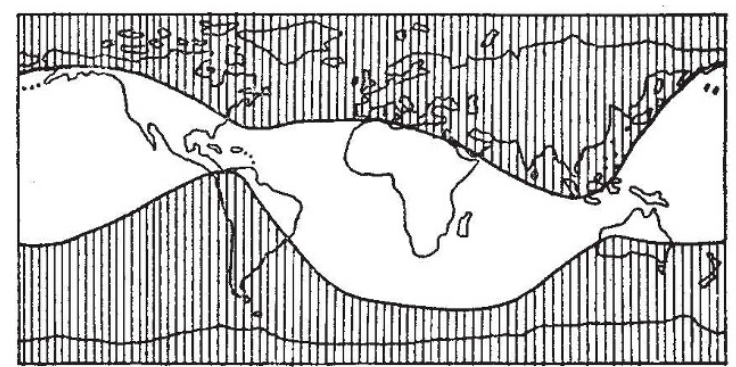

Fig.7.

the principal planes of that ellipsoid which most nearly represents the elevation of the surface above or its depression below the surface of the ocean, or the geoid. The result is an equatorial region of depression, which spreads north and south unequally in different parts and forms a sort of immense Mediterranean, containing two great basins, and separating a northern region of elevation from a southern. The northern region of elevation occupies the northern part of the Atlantic Ocean and runs down to and across the equator in the neighbourhood of Borneo. The southern region of elevation occupies the southern part of the Pacific Ocean, and it runs up to and across the equator in the neighbourhood of Peru. The chart of the harmonic is shown in Fig. 7 . The equatorial regions

1 In this figure, and in the following figures, regions of elevation are haded, and regions of depression are left blank. 
of elevation given by the analysis are near the ends of a diameter, as we should expect.

It has not been necessary to enter into a minute description of the harmonics of the first and second degrees, because they represent very simple things-a shifting of the surface to one side and a distortion of it into an ellipsoid. The harmonics of the third degree are not so familiar. There are essentially four of them, each specify-

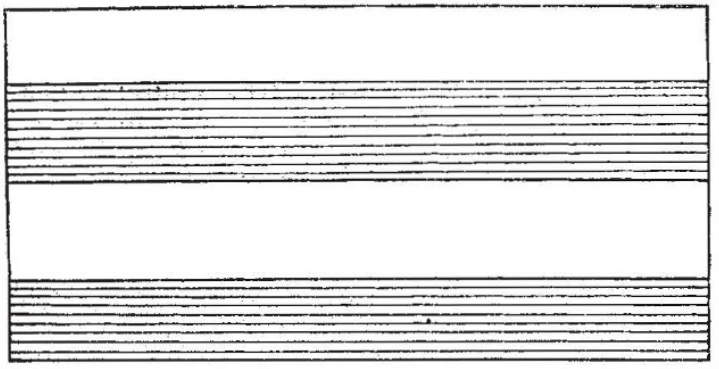

Fig. 8.

ing a standard pattern of deformation. The first of these, the zonal harmonic, gives us a division of the surface into two polar caps and two zones by means of the equator and the parallels of latitude about ${ }_{5} \mathrm{I}^{\circ}$ north and $5 \mathrm{I}^{\circ}$ south. Alternate zones are depressed and elevated, as shown in Fig. 8. The existence of an Antarctic continent and an Arctic Ocean is specially associated with the presence of this harmonic, and the disproportion of the continental

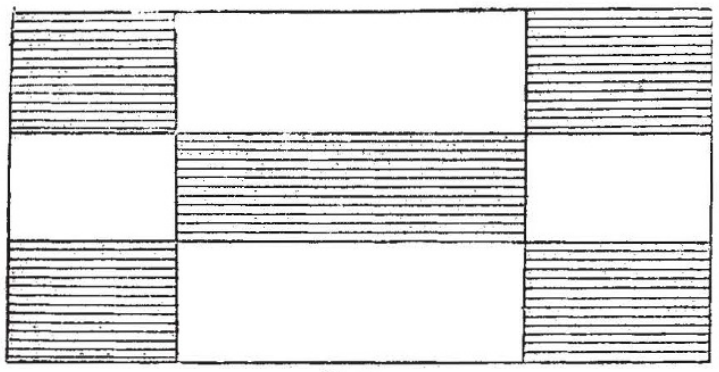

Fig.9.

areas in the northern and southern hemispheres is also connected with it. The second of the harmonics of the third degree, the tesseral harmonic of rank I, gives us a division of the surface into six half-zones by means of a complete meridian circle and the parallels of latitude about $27^{\circ}$ north and $27^{\circ}$ south. Alternate half-zones are depressed and elevated as shown in Fig. 9. The combined effect represented by the zonal harmonic and the tesseral

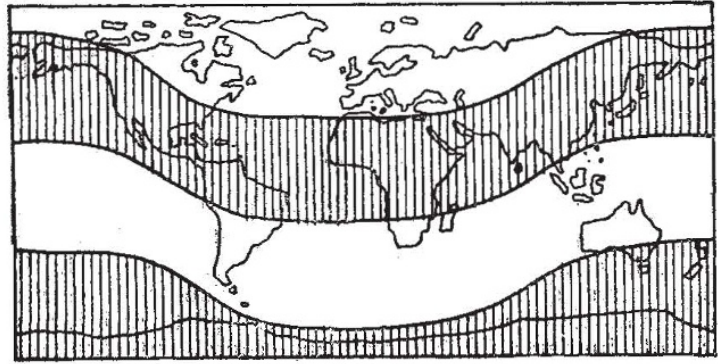

Fig. 10.

harmonic of rank $I$ is a furrowed surface with an Arctic region of depression extending southwards in the direction of the Atlantic, a zone of elevation which runs across the Atlantic, South America, and Africa, and then turns northwards at either end, a zone of depression with the same kind of contour, and an Antarctic region of elevation which extends northwards in the direction of Australasia. These regions are shown in Fig. Io. I have recorded the result of combining these two harmonics because they represent the particular effects that would be produced by the interaction of two causes-the rotation, and the eccentric position of the centre of gravity. The third type of harmonics of the third degree, the tesseral harmonic of rank 2, gives us a division of the surface into octants by means of the equator and two complete meridian circles. Alternate octants are elevated and depressed as shown in Fig. II. We

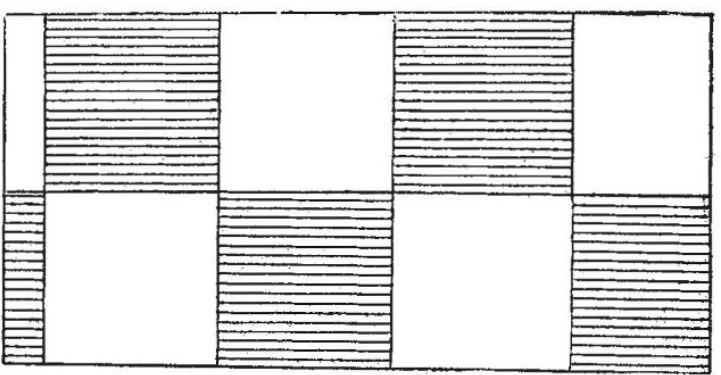

Fig. II.

can name the octants where there is elevation: Asia, Australasia, North America, South America. The harmonic of this type is certainly prominent. It is specially associated with the skew position of South America to the east of North America. The fourth type of harmonics of the third degree, the sectorial harmonic, gives us a division of the surface into six sectors by means of three complete meridian circles. Alternate sectors are depressed and

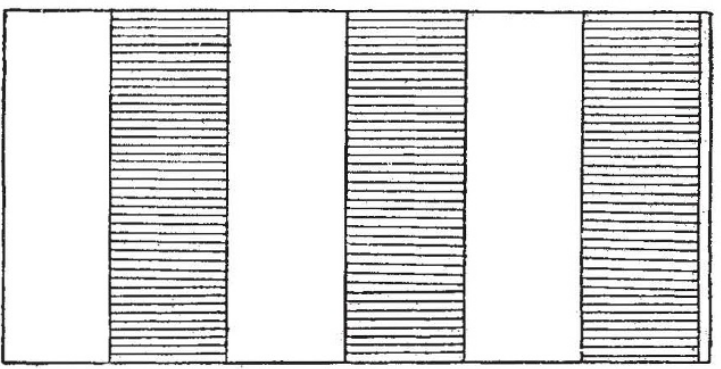

Fig. 12 .

elevated as shown in Fig. 12. The southward tapering of Africa is specially associated with the harmonic of this type. The combined effect of all the harmonics of the third degree is shown in Fig. I3. It represents the sphere deformed into a sort of irregular pear-shaped surface. The stalk of the pear is in the southern part of Australia and contains Australasia and the Antarctic continent. This is surrounded on all sides but one (towards South America)

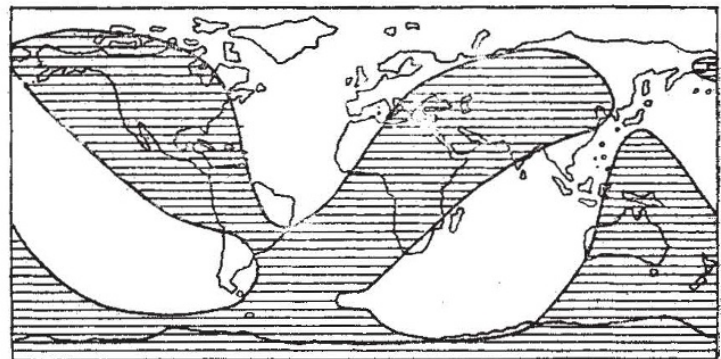

Fig.13.

by a zone of depression, the waist of the pear. This, again, is surrounded on all sides but one (towards Japan) by a zone of elevation, the protuberant part of the pear and finally we find the nose of the pear in the central Atlantic between the Madeiras and the Bermudas. 1 do not, however, wish to emphasise the resemblance of the surface to a pear or any other fruit, but prefer to describe it as an harmonic spheroid of the third degree. Another 
way of regarding it would be as a surface with ridges and furrows. From a place in the South Atlantic there run three ridges: one north-westwards across America, a second north-eastwards across Africa and Asia, and the third southwards over the Antarctic continent, continuing northwards across Australia nearly to Japan. From the Sea of Okhotsk there run three furrows: one south-westwards across Japan, the Malay Peninsula, and the Indian Ocean; a second south-eastwards across the Pacific; and the third northwards over the Arctic Ocean, continuing southwards by way of the Atlantic. Harmonics of the first and third degrees have in common the character of giving depression at the antipodes of elevation; the harmonics of the second degree give depression at the antipodes of depression and elevation at the antipodes of elevation. The maxima of the harmonics of the first and third degrees are found to be rather greater than the maximum of the harmonic of the second degree. Of three quantities to be added together the two larger ones agree in giving depression at the antipodes of elevation; a result which is in accordance with the fact that most continents have oceanic antipodes.

When we superpose the effects represented by all the various harmonics of the first, second, and third degrees, so as to make, as it were, a composite photograph of all the various elevations and depressions represented by them severally, each in its appropriate amount as determined by the harmonic analysis, we find the curve shown in Fig. I4 as the theoretical curve of separation between regions of elevation and depression which are approximately equal in area. I showed before a smoothed curve (Fig. 3) which I proposed to take as representing the facts to be

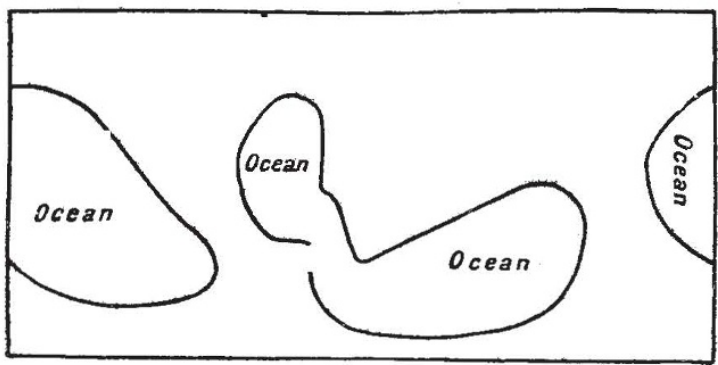

Fig. 14.

accounted for. The resemblance of the two curves seems to be striking. Incidentally it has been noticed how the prominent features of the distribution of continent and ocean are associated with the presence of various harmonics. As regards the contour of the great ocean basins, we seem to be justified in saying that the earth is approximately an oblate spheroid, but more nearly an ellipsoid with three unequal axes, having its surface furrowed according to the formula for a certain spherical harmonic of the third degree, and displaced relatively to the geoid towards the direction of the Crimea.

As regards the amount of elevation and depression in different parts, the agreement of the theory with the facts is not so good. The computed elevation is too small in Southern Africa, Brazil, and the southern part of South America, too great in the Arctic regions, to the south of of Australasia, and in the Mediterranean region. There are many reasons why we could not expect the agreement to be very good. One is the roughness of the method of harmonic analysis that was used. But there is also the fact that many causes must have contributed to the shaping of our actual continents and oceans besides those which have been taken into account in the theory. It appears, however, that the broad general features of the distribution of continent and ocean can be regarded as the consequences of simple causes of a dynamical character: eccentric position of the centre of gravity, arising from a past state of inadequate resistance to compression, an inherited tendency, so to speak, to an ellipsoidal figure, associated with the attraction of the moon in a bygone age, the rotation, and the interactions of these various causes.

In attempting to estimate the bearing of the theory on geological history we must be guided by two considerations. The first is that the earth is not now gravitationally unstable. From observations of the propagation of earthquake shocks to great distances, we can determine the average resistance to compression, and we find that this resistance is now sufficiently great to keep in check any tendency to gravitational instability. The eccentric position of the centre of gravity must be regarded as a survival from a past state in which the resistance to compression was not nearly so great as it is now. The second guiding consideration is that, according to the theory, the inequalities which are expressed by spherical harmonics of the third degree are secondary effects due to the interaction of the causes which give rise to inequalities expressed by harmonics of the first and second degrees. We should expect, therefore, that the inequalities of the third degree would be much smaller than those of the first and second degrees; but the harmonic analysis shows that the three inequalities are entirely comparable. We must conclude that the harmonics of the first and second degrees which we can now discover by the analysis are survivals from a past state, in which such inequalities were relatively more important than they are now. Both these considerations point in the same direction, and they lead us to infer that certain sæcular changes may have taken place in the past, and may still be going on. Sixty-nine years ago Charles Darwin wrote: "The form of the fluid surface of the nucleus of the earth is subject to some change the cause of which is entirely unknown, and the effect of which is slow, intermittent, but irresistible." Forty-two years later Sir George Darwin showed that any ellipsoidal inequality in the figure must be gradually destroyed by an irreversible action of the same nature as internal friction or viscosity. The same may be said of a state in which the centre of gravity does not coincide with the centre of figure when the resistance to compression is great enough to keep in check the tendency to gravitational instability. The state would be changed gradually in such a way as to bring the centre of gravity nearer to the centre of figure. $\AA$ symptom of such changes might be the occurrence of great subsidences in the neighbourhood of the Crimea, where we found the maximum of the first harmonic. Such subsidences are supposed by geologists to have taken place in rather recent times. Symptoms of the diminution of the inequalities expressed by harmonics of the second degree would be found in the gradual disappearance of seas forming part of the great depression which was described above as a sort of immense Mediterranean (cf. Fig. 7), in the destruction and inundation of a continent in the northern Atlantic and in a gradual increase of depth of the Southern Pacific. The disappearance of seas from a vast region surrounding the present Mediterranean basin, and containing the Sahara and Southern Asia as far east as the Himalayas, is one of the best ascertained facts in geological history; and the belief in the destruction of a north Atlantic continent is confidently entertained. In parts of the Southern Pacific a depression represented by harmonics of the third degree is superposed upon an elevation represented by harmonies of the second degree, and we should therefore expect. to find the depth of the ocean to be increasing gradually in this region. The region in question is that of the coral reefs and coral islands, such as Funafuti, and the result is in accord with Darwin's theory of the formation of coral reefs. So far as the general distribution of the mass within the earth is concerned, the reduction of the inequalities of the first and second degrees would seem to have already proceeded very far; for we are assured by geodesists that harmonics of the first degree, and those of the second degree which do not represent the effect of the rotation, are far from prominent in the figure of the geoid-much less prominent than we found them to be in the distribution of continent and ocean. We infer that the inequalities of the first and second degrees must have been progressively diminished in comparison with those of the third degree. The general result of such changes would be a gradual diminution of the depths and extents of the oceans which correspond with the harmonics of the first and second degrees, and a compensating increase in the depths and extents of the oceans which correspond with the harmonic of the third degree. To see the character of the changes which wotld

No. I9? O, VOL. 757 
thus be brought about, we may examine a figure which shows the composite elevations and depressions that are represented by harmonics of the first and second degrees, and, separately, those which are represented by harmonic: of the third degree. In Fig. I5 the composite elevations of the first and second degrees are shaded vertically, and the elevations of the third degree are shaded horizontally. 'The deep parts of the Atlantic that border the coasts everywhere from Brazil to Ashanti are regions in which a depression represented by the third harmonic is superposed upon an elevation represented by the other two harmonics, and the same is true of the deep parts of the Indian Ocean which border the shores of Africa and Asia from Madagascar to Burmah. The deep parts of the Pacific that border the western coast of America from Alaska to Ch: are regions in which an elevation represented by the third harmonic is superposed upon a depression represented by the other harmonics. These observations suggest that in the greater part of the Atlantic and the northern and western parts of the Indian Ocean the direction of sæcular change may have been that of an advance of the ocean to encroach upon the continental region, while in the Pacific Ocean on the American side the direction of sæcular change may have been that of a retreat of the ocean, permitting an extension of the continental region. This difference would lead us to expect different types of coast in the two regions, and such a difference has been observed. Whereas in the Atlantic region, with few exceptions, the coast cuts across the directions of the mountain chains, in the Pacific region on the American side the coast generally corresponds

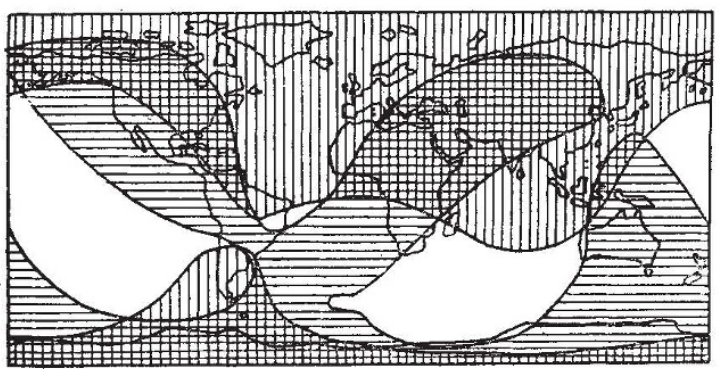

Fig. 15.

in direction with the neighbouring mountain chains of the continent. The deep parts of the Pacific which are nearest to the Asiatic coast from Kamchatka to Siam are regions where a moderate depression represented by the third harmonic is superposed upon a moderate elevation represented by the other harmonics. These shores of the Pacific are distinguished by the wide margin which separates the deep ocean from the coast of the continent. It might perhaps be desirable to recognise in this region a type of coast differing from the two main types associated with the Atlantic and the American side of the Pacific. The analysis does not represent South Africa or the southern parts of South America sufficiently well to warrant us in expecting these regions to exhibit one type rather than the other; but the way in which Australia is represented, as an elevation of the third degree superposed upon a depression of the first, suggests that the coasts of Australia, and especially the, eastern coast where the elevation in question is greater, should be of the same type as the American shores of the Pacific; and it is the fact that the mountain chains of Queensland and New South Wales run parallel to the neighbouring coasts. There seems therefore to be much evidence to support the view that the direction of sæcular change has been that of diminishing the prominence of the inequalities of the first and second degrees in comparison with those of the third degree. The process by which such changes would be brought about would be of the nature of relief of strain, expressing itself in occasional fractures of no very great magnitude; and such fractures would be manifested at the surface as earthquakes. Seismic and volcanic activities constitute the mechanism of the process of change. These activities are spasmodic and irregular, but the effect of them is cumulative. For this reason they tend in the course of ages to transform the shape of the NO. I970, VOL. 76] earth from one definite type to another. The diminishing speed of the earth's rotation is another cause of change which appears to produce an alternating rather than a cumulative effect. On the one hand it tends to diminish that tendency, which we noted above, to draw the waters of the ocean towards equatorial regions; on the other hand it must result in an actual reduction of the equatorial protuberance of the earth's figure. This reduction can only be effected by seismic activity expressed by subsidences in equatorial regions. The effect which would in this way be produced in the distribution of continent and ocean would appear to be that there would be long periods in which the ocean would tend to advance towards the Arctic and Antarctic regions, interrupted by shorter periods in which it would tend to retreat towards the neighbourhood of the equator.

The theory which I have tried to explain is a tentative one, and further investigation may prove it to be untenable but it is to its credit that, besides tracing to dynamical causes the existing distribution of continent and ocean, it offers an explanation of the difference between the Atlantic and Pacific types of coast, it gives indications of a possible account of those alternations of sea and land which first led to the study of geology, and it suggests an origin for Charles Darwin's unknown force the operation of which is slow and intermittent, but irresistible.

\section{NOTES.}

NExT year's meeting of the British Nedical Association will be held at Sheffield under the presidency of Mr. Simeon Snell. This year's meeting is at presnt in progress at Exeter. On Tuesday last the presiffM, Dr. Henry Davy, delivered his address, taking as his subject "Science in its Application to National Health."

THE Nimrod, in which Mr. E. H. Shackleton's expedition will proceed to the Antarctic regions, sailed from the Thames on July 30 with Lieut. Rupert England in command. Lord Kelvin has presented to the expedition a standard compass and sounding instryments. The Admiralty is lending a compass, chronomet $\mathrm{s}$, charts, and sounding apparatus, as well as three Lofd-Creak Dip instruments for the landing party. Whtchs are being supplied by the Royal Geographical Society, and, in addition, the vessel will be equipped with a liquid steering compass and a special pole compass. The members of the expedition on board the Nimrod are Mr. James Murray, the biologist of the expedition; Mr. W. A. Michell, surgeon and zoologist; and Mr. A. F. Mackay, the junior surgeon of the landing party, who will also engage in zoological work. At Lyttelton, New Zealand, the remaining members of the expedition will join the ship. These include, besides Mr. Shackleton, Mr. E. Marshall, senior surgeon of the shore party and cartographer of the expedition; Lieut. Adams, R.N.R., who will be in charge of the meteorological work; and Sir Philip Brocklehurst, for survey work and field geology. Dr. David, professor of geology in Sydney University, has arranged to accompany the expedition south to King Edward VII. Land.

THE weather still continues very cool for the time of year, but on the whole the conditions lately ave been somewhat dry. At Greenwich there has bren no year since 1888 with so few warm days 1 in July, and the thermometer has not once touched $\beta, 1$. The total rainfall for the month is less than an ifh, whilst the average for the past sixty years in July is 2.40 inches. The aggregate rainfall for the first eight weeks of summer, to July 27 , is less than the average in the north-east, east, and south of England, and in the Channel Islands, but in every other district of the United Kingdom it is in excess of the normal. The greatest excess for the summer 